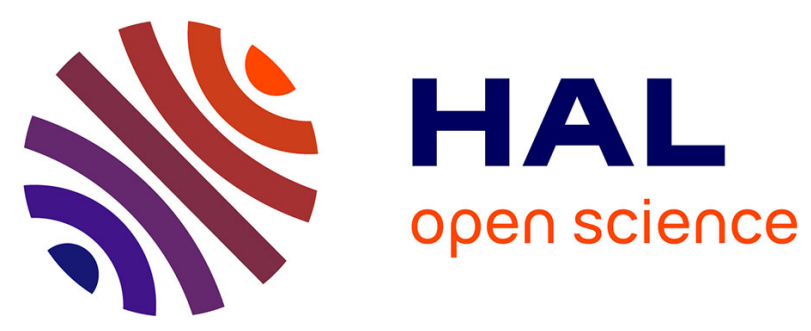

\title{
New Parameterizations for Neutral and Ion-Induced Sulfuric Acid-Water Particle Formation in Nucleation and Kinetic Regimes
}

Anni Määttänen, Joonas Merikanto, Henning Henschel, Jonathan Duplissy, Risto Makkonen, Ismael K. Ortega, Hanna Vehkamäki

\section{To cite this version:}

Anni Määttänen, Joonas Merikanto, Henning Henschel, Jonathan Duplissy, Risto Makkonen, et al.. New Parameterizations for Neutral and Ion-Induced Sulfuric Acid-Water Particle Formation in Nucleation and Kinetic Regimes. Journal of Geophysical Research: Atmospheres, 2018, 123 (2), pp.12691296. 10.1002/2017JD027429 . hal-01710882

\section{HAL Id: hal-01710882 \\ https://hal.science/hal-01710882}

Submitted on 16 Feb 2018

HAL is a multi-disciplinary open access archive for the deposit and dissemination of scientific research documents, whether they are published or not. The documents may come from teaching and research institutions in France or abroad, or from public or private research centers.
L'archive ouverte pluridisciplinaire HAL, est destinée au dépôt et à la diffusion de documents scientifiques de niveau recherche, publiés ou non, émanant des établissements d'enseignement et de recherche français ou étrangers, des laboratoires publics ou privés. 


\section{New parameterizations for neutral and ion-induced sulfuric acid-water particle formation in nucleation and kinetic regimes}

Anni Määttänen ${ }^{1}$, Joonas Merikanto ${ }^{2}$, Henning Henschel ${ }^{3,4}$, Jonathan

Duplissy $^{3,5}$, Risto Makkonen ${ }^{3}$, Ismael K. Ortega ${ }^{6}$ and Hanna Vehkamäki ${ }^{3}$

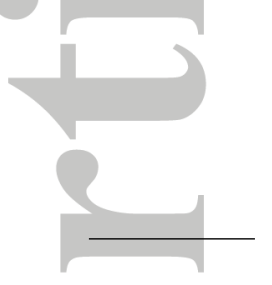

A. Määttänen, anni.maattanen@latmos.ipsl.fr

${ }^{1}$ LATMOS/IPSL, UVSQ Université

Paris-Saclay, UPMC Univ. Paris 06, CNRS,

11 boulevard d'Alembert, 78280

Guyancourt, France.

${ }^{2}$ Finnish Meteorological Institute,

Helsinki, Finland.

${ }^{3}$ Department of Physics, University of

Helsinki, Helsinki, Finland.

${ }^{4}$ Now at: Research Unit of Medical

Imaging, Physics and Technology,

University of Oulu, Oulu, Finland.

This article has been accepted for publication and undergone full peer review but has not been through the copyediting, typesetting, pagination and proofreading process, which may lead to differences between this version and the Version of Record. Please cite this article as doi: 10.1002/2017JD027429

(C)2017 American Geophysical Union. All Rights Reserved. 


\section{Abstract.}

We have developed new parameterizations of electrically neutral homogeneous and ion-induced sulfuric acid - water particle formation for large ranges of environmental conditions, based on an improved model that has been validated against a particle formation rate data set produced by Cosmics Leaving OUtdoor Droplets (CLOUD) experiments at CERN. The model uses a

thermodynamically consistent version of the Classical Nucleation Theory normalized using quantum chemical data. Unlike the earlier parameterizations for $\mathrm{H}_{2} \mathrm{SO}_{4}-\mathrm{H}_{2} \mathrm{O}$ nucleation, the model is applicable to extreme dry conditions where the one-component sulfuric acid limit is approached. Parameterizations are presented for the critical cluster sulfuric acid mole fraction, the critical cluster radius, the total number of molecules in the critical cluster, and the particle formation rate. If the critical cluster contains only one sulfuric acid molecule, a simple formula for kinetic particle formation can be used:

this threshold has also been parameterized. The parameterization for electrically neutral particle formation is valid for the following ranges: temperatures $165-400 \mathrm{~K}$, sulfuric acid concentrations $10^{4}-10^{13} \mathrm{~cm}^{-3}$ and relative hu-

${ }^{5}$ Helsinki Institute of Physics, University of Helsinki, Helsinki, Finland.

${ }^{6}$ Onera-The French Aerospace Lab, F-91761 Palaiseau, France.

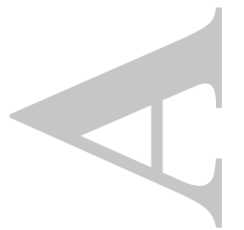


midities $0.001-100 \%$. The ion-induced particle formation parameterization is valid for temperatures $195-400 \mathrm{~K}$, sulfuric acid concentrations $10^{4}-10^{16} \mathrm{~cm}^{-3}$ and relative humidities $10^{-5}-100 \%$. The new parameterizations are thus applicable for the full range of conditions in the Earth's atmosphere relevant for binary sulfuric acid - water particle formation, including both tropospheric and stratospheric conditions. They are also suitable for describing particle

formation in the atmosphere of Venus.

\section{Keypoints:}

- Our $\mathrm{H}_{2} \mathrm{SO}_{4}-\mathrm{H}_{2} \mathrm{O}$ parameterizations reproduce state-of-the-art experimental and theoretical results for large ranges of environmental conditions

- We recommend replacing Vehkamäki et al. [2002]; Vehkamäki et al. [2003] neutral particle formation parameterizations with ours and adding the ioninduced pathway

- Combination of neutral and ion-induced pathways and the kinetic regime is required to describe $\mathrm{H}_{2} \mathrm{SO}_{4}$ particle formation on Earth and Venus

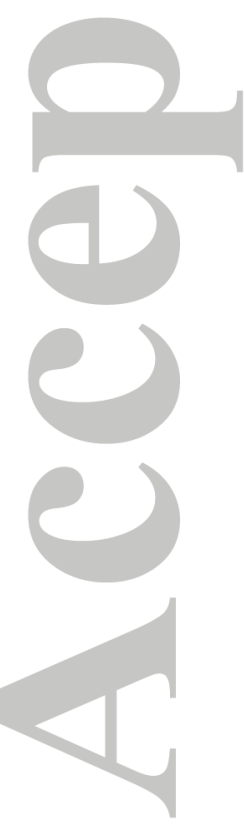




\section{Introduction}

Aerosols affect Earth's climate by scattering solar radiation and acting as cloud condensation nuclei [Boucher et al., 2013] and thus they significantly affect the radiation balance within the Earth's atmosphere. Sulfur is transmitted into the Earth's atmosphere as $\mathrm{SO}_{2}$ and other gaseous sulfur species. These species are transformed into gas phase sulfuric acid through atmospheric oxidation. Sulfuric acid generates new atmospheric aerosol particles through secondary particle formation processes. Global aerosol models show that secondary particles formed in the atmosphere dominate the total global aerosol number concentrations, and generate up to half of global cloud condensation nuclei (CCN) [Spracklen et al., 2008; Merikanto et al., 2009]. Observed particle formation rates are often proportional to the abundance of gaseous sulfuric acid [Weber et al., 1996; Sihto et al., 2006; Kuang et al., 2008; Petäjä et al., 2009], suggesting that sulfuric acid is a key compound in atmospheric new particle formation in the Earth's troposphere. In the lower troposphere also additional compounds are required to stabilize the sulfuric acid clusters [Sipilä et al., 2010; Zhao et al., 2010; Petäjä et al., 2011] and allow their growth to atmospherically relevant sizes [Ortega et al., 2012]. In the upper troposphere pure sulfuric acid-water particle formation is likely an efficient mechanism for new particle formation [Kirkby et al., 2011; Merikanto et al., 2016]. A significant fraction of boundary layer CCN originate from particles formed in the upper troposphere [Raes, 1995; Merikanto et al., 2009].

Besides its tropospheric significance, the sulfuric acid -water particle formation mechanism is likely responsible for generating a persistent aerosol layer in the stratosphere 
(the Junge layer) composed of sulfuric acid-water particles [Lee et al., 2003]. This layer has a predominantly cooling effect on the global climate via their ability to scatter solar radiation [Solomon et al., 2011], and they also play a role in ozone destruction processes through heterogeneous chemical reactions [Peter and Grooß, 2012]. Volcanic eruptions inject variable amounts of gaseous sulfur and sulfate particles into the Earth's stratosphere, leading to variations in the sulfate aerosol concentrations [Vernier et al., 2011; Sawamura

et al., 2012], while also changes in the anthropogenic sulfur dioxide emissions can lead to substantial changes in the lower stratospheric sulfate loading [Pitari et al., 2002; Hofmann et al., 2009; Hommel et al., 2015]. These effects need to be taken into account in climate models extending up to the stratosphere.

Sulfate aerosols are also important components of present and past atmospheres of other planets of the solar system, such as Venus and Early Mars [McGouldrick et al., 2011]. Venus' clouds, which cover the whole planet and are responsible for Venus' high visible wavelength albedo [Esposito et al., 1983], are mainly formed of sulfuric acid solution droplets at around 50-70 km above the Venusian surface at conditions comparable to those on the Earth with temperatures and pressures of the order of $T=200-350 \mathrm{~K}$ and $p=0.01-1$ bar. These optically thick $\left(\tau_{V I S} \approx 30\right)$, layered clouds distributed over $20 \mathrm{~km}$ in altitude effectively block the sunlight from reaching the surface of the planet, where only a few percent of solar radiation is received. The surface temperatures on Venus are, however, on average around $700 \mathrm{~K}$ because of the greenhouse effect of the very thick $\mathrm{CO}_{2}$ atmosphere, and without the clouds the planet would be even hotter.

Binary sulfuric acid - water particle formation can play a role in the formation of the clouds in Venus. Previous models have assumed [James et al., 1997; McGouldrick and 
Toon, 2007; Gao et al., 2014] that cloud droplet formation involves heterogeneous nucleation of sulfuric acid on pre-existing particles. The insufficiency of the data obtained by space missions has prevented constraining the identities of the possible CCN, although several candidates have been suggested, such as sulfur allotropes and meteor dust [Young, 1983; Gao et al., 2014]. However, the conditions in Venus could also allow the droplet formation to be initiated by homogeneous or ion-induced unary/binary nucleation, followed by subsequent growth to cloud droplet sizes. In the cloud formation altitudes, the sulfuric acid concentrations are in the range $10^{9}-10^{15} \mathrm{~cm}^{-3}$, and relative humidities (over a flat surface of pure water) well below $1 \%(0.003-0.03 \%)$ [for a recent review on the atmospheric composition of Venus, see Krasnopolsky and Lefèvre, 2013, and references therein]. In the absence of direct evidence, no particle formation mechanism can be excluded. Simple heterogeneous activation of some type of condensation nuclei is fairly easy to implement to microphysical models [James et al., 1997; McGouldrick and Toon, 2007; Gao et al., 2014] and it provides a simple and easily tunable way to form the clouds. However, if modelers wish to implement also homogeneous particle formation pathways, the Vehkamäki et al. [2002] parameterization is not valid for a wide enough range of relative humidities. In addition, ion-induced nucleation has not been presented as a possibility before, but the model results on atmospheric ionization on Venus [Plainaki et al., 2016; Michael et al., 2009] imply it could play a significant role.

Large scale atmospheric aerosol models require computationally efficient parameterized representations of the particle formation process in various ambient conditions, either in forms of parameterized functions or look-up tables covering various environmental conditions. Such representations can be produced in at least two ways: one can either develop 
parameterizations based on theoretical constructs that take into account the physical properties of the system, or one can build parameterizations based solely on experimental particle formation data. Since particle formation has a complex dependence on the concentrations of participating species and on temperature, the latter approach, while possibly more accurate for describing measured data, is not trustworthy for conditions outside the measurement range. Therefore, it is much safer to base parameterizations on a theory that can reproduce the measured data and predict the dynamics of particle formation outside the measured range.

The physical understanding of atmospheric particle formation processes has not been on a firm basis, even for the relatively simple binary sulfuric acid - water system. Different theoretical formulations for binary particle formation for the neutral system [ Wexler et al., 1994; Pandis et al., 1994; Kulmala et al., 1998; Vehkamäki et al., 2002; Kazil and Lovejoy, 2007; Yu, 2008], and for the ion-induced system in particular [Modgil et al., 2005; Kazil and Lovejoy, 2007; Yu, 2010], can produce binary formation rates that vary by several orders of magnitude [Zhang et al., 2010]. For example, the theory used by $Y u$ [2010] probably contains a double counting of the dipole-dipole interaction [Donald and Williams, 2008], leading to too high binding energies and predictions of the formation rate [Donald et al., 2011].

Lack of precision and coverage of binary particle formation experiments that could be used for the quantitative validation of theoretical models has also contributed to the variation in the formation rates predicted by the different parameterizations. Furthermore, the experimental particle formation rates have suffered from two experimental limitations: 1) the contamination by minute, but significant, levels of trace gases, such as ppt-level 
concentrations of ammonia [Kirkby et al., 2011], and 2) a significant difference between the extremely small critical cluster size and the minimum measurable particle size [Sipilä et al., 2010]. Recent advances in mass spectrometry have made it possible to monitor lowlevel impurities in the formed molecular clusters and new particle detectors have achieved sufficient sensitivity to directly count particles below $3 \mathrm{~nm}$ in diameter. Using these new detectors, the Cosmics Leaving OUtdoor Droplets (CLOUD) project in CERN has, for

the first time, provided accurate and demonstrably contaminant-free measurements of binary sulfuric acid - water particle formation allowing precise model-data comparisons [Duplissy et al., 2016]. The extensive formation rate data set provided by Duplissy et al. [2016] covers sulfuric acid concentrations from $10^{5}$ to $10^{9} \mathrm{~cm}^{-3}$, relative humidities from $11 \%$ to $58 \%$, temperatures from $207 \mathrm{~K}$ to $299 \mathrm{~K}$, and total ion concentrations from 0 to 6800 ions $\mathrm{cm}^{-3}$.

The Classical Nucleation Theory [CNT, Doyle, 1961; Binder and Stauffer, 1976; Trinkaus, 1983; Seinfeld and Pandis, 1998] is an old and elegant description of the nucleation process, but suffers from the assumption of macroscopic bulk properties for matter at microscopic scales. In the new parameterization we use the thermodynamically consistent Classical Nucleation Theory normalized with quantum chemical data on sulfuric acid hydration as described in Merikanto et al. [2016]. The model has been successfully validated against the CLOUD experiments [Duplissy et al., 2016]. The framework of Classical Nucleation Theory ensures a physically based behavior for the developed parameterizations even outside the experimental range of the CLOUD data set [Duplissy et al., 2016; Merikanto et al., 2016].

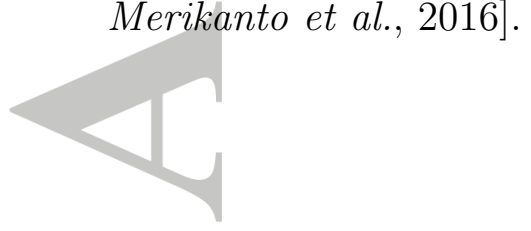

(C)2017 American Geophysical Union. All Rights Reserved. 
In this paper we present new parameterizations of neutral and ion-induced sulfuric acidwater particle formation. The neutral sulfuric acid -water parameterization can be viewed as an update to the [Vehkamäki et al., 2002] and [Vehkamäki et al., 2003] particle formation parameterizations that are widely used in global and aerosol dynamics models [see, for example, Korhonen et al., 2004; Vignati et al., 2004; Stier et al., 2005; Bauer et al., 2008; Merikanto et al., 2009]. The temperature and sulfuric acid concentration ranges of the new parameterizations are wider than those of Vehkamäki et al. [2002] and Vehkamäki et al. [2003], and the calculations are also extended to very low relative humidities. This was motivated by the present development of sulfuric acid cloud models for the Venusian atmosphere, which is much drier than the Earth's atmosphere. We have also developed an ion-induced particle formation parameterization based on the Merikanto et al. [2016] model validated by the CLOUD measurements of ion-induced particle formation.

\section{Methods}

\subsection{Model for electrically neutral particle formation}

The thermodynamic data and the applied theoretical model used for generating the parameterizations are described in Merikanto et al. [2016]. In the framework of the revised theory of Merikanto et al. [2016], both neutral and ion-induced particle formation can take place in the range of parameterized conditions either through nucleation, where particle formation involves crossing of the free energy barrier for formation of stable particles, or through kinetic particle formation, where such a free energy barrier does not exist. Throughout the paper we generally employ the term "particle formation" to describe the process in general, but may substitute it with "nucleation" when the particle formation 
involves a free energy barrier. When the process is barrierless we use the term "kinetic particle formation".

The model behind the present parameterization differs from the model used in Vehkamäki et al. [2002] and Vehkamäki et al. [2003] in three respects. First, we now use analytical formulae for the second derivatives of the formation free energy, since the numerical derivatives were unstable at the one-component limit. Second, the cluster distribution in the nucleating vapor is normalized via a known reference concentration, which in Noppel et al. [2002] and Vehkamäki et al. [2002] was taken to be the sulfuric acid dihydrate. Here, we use the full hydrate distribution in the normalization process instead of only the dihydrate. This modified approach ensures a smoother transition into a one-component system in the pure sulfuric acid limit. Third, the reference sulfuric acid monomer hydrate distribution is based on more accurate quantum chemical results [Kurtén et al., 2007; Henschel et al., 2014] than in Vehkamäki et al. [2002] and Vehkamäki et al. [2003].

The binary particle formation rates at conditions close to zero relative humidity tend towards one-component nucleation rates, but the binary theory cannot mathematically handle zero relative humidity due to singularities in the kinetic prefactor of the nucleation rate expression in this case. Furthermore, the zero relative humidity limit of the binary kinetic prefactor does not approach exactly the unary prefactor, producing an inconsistency, albeit small, between the binary and unary models. For mathematical completeness, we discuss the difference in binary and unary prefactors in Appendix A. Within the accuracy required for the parameterization, the predicted particle formation approaches one-component sulfuric acid particle formation at very low relative humidities 
(where mole fraction of acid in the cluster $x>0.99$ ), and at zero relative humidity the one-component theory has been used to produce the data. However, the parameterizations do not cover the exact $R H=0$ value, since they contain logarithms of $R H$.

In the presence of water, the total concentration of sulfuric acid molecules can be significantly larger than the concentration of free sulfuric acid monomers, and a large fraction of acid molecules is bound to hydrates. In the conditions of the Earth's atmosphere, the concentration of water is approximately ten orders of magnitude higher than that of sulfuric acid, and thus the total concentration of water molecules can be considered equal to the concentration of free water monomers, as pure water cluster formation does not play a significant role either. In the very dry conditions studied in this work, the previous assumption is not necessarily true and the distinction between total concentration of water and concentration of free water molecules must be kept in mind. By definition, at a fixed temperature the relative humidity used as an input parameter in the parameterizations is proportional to the concentration of free water molecules instead of the total concentration of water molecules.

\subsection{Model for ion-induced particle formation}

In the Earth's atmosphere, the dominant molecular anions forming the cores of negatively charged cluster ions are mostly the conjugate bases of the strongest atmospheric acids $\left(\mathrm{HSO}_{4}^{-}, \mathrm{NO}_{3}^{-}, \mathrm{Cl}^{-}\right)$, which in turn are small inorganic molecules. Similarly, the dominant atmospheric molecular cations tend to be the conjugate acids of the strongest bases (e.g. $\mathrm{NH}_{4}^{+}$, pyridium, different aminium ions), though $\mathrm{H}_{3} \mathrm{O}^{+}$-based clusters are also often present due to the much larger concentration of water. With the possible exception of some of the nitrogen-containing organic cations, these molecular ions are all rather 
small - well below $1 \mathrm{~nm}$ in diameter [Hirsikko et al., 2011; Ehn et al., 2010; Beig and Brasseur, 2000].

Though the precise chemical identities of the acids and bases present of course vary between different planetary atmospheres, the fundamental result that atmospheric molecular ions tend to be rather small is likely universal, especially for the anions. As the complicated large organic molecules present in our atmosphere are almost invariably bio-

genic, it could even be argued that the probability of encountering large molecular ions should be even smaller in other planetary atmospheres compared to ours.

For classical ion-induced nucleation theory (where the free energy of formation as a function of cluster size exhibits a barrier), the equation yielding the critical cluster radius has two solutions: a stable (in one dimensional representation free energy minimum) pre-nucleation cluster representing the ion surrounded by a few molecules, $r_{1}^{*}$, and the actual metastable (free energy maximum) critical cluster $r_{2}^{*}$, with $r_{2}^{*}>r_{1}^{*}$ [see Figure 2 of Merikanto et al., 2016]. The classical version of ion-induced nucleation theory used in this work assumes that the size of the bare ion is smaller than the lower radius $r_{\text {ion }}<r_{1}^{*}$, and in this case the size of the ion does not affect the energetics of nucleation. While an extension of the theory to relax this condition is possible, it is beyond the scope of this study. Thus, care should be taken to ensure that the ions are small enough to satisfy this condition always when this parametrization is applied. For the whole validity range of the parametrization the radius $r_{1}^{*}$ varies between $0.6 \mathrm{~nm}-1.4 \mathrm{~nm}$. Ion size has a very minor effect on the kinetics of nucleation, which has been ignored in this study as this produces an error insignificant compared to other sources of uncertainty in the nucleation 
rates. We have used ion radius $0.487 \mathrm{~nm}$ corresponding to the bisulphate ion in all the calculations.

It should be noted that in cases where the core molecular ions are formed by charging large organic molecules (e.g. biomolecules), application of classical ion-induced nucleation theory may suffer from difficulties above and beyond those related to ion size. In such cases, the negative or positive charge is very likely localized to one or more specific

functional groups of the molecule (e.g. sulfate, nitrate or carboxylate groups in the case of anions). Thus, treating the molecular ion as a uniformly charged sphere (an excellent approximation for simple inorganic ions such as bisulfate or ammonium) may lead to large errors even if the ion size is appropriately accounted for.

In laboratory conditions, molecular ions of arbitrary size can be created for example in the form of charged metal clusters. In contrast to the charged biomolecules discussed above, heterogeneous nucleation onto such core ions may in principle be described fairly well by classical theory, as the charge can be delocalized over the entire (more or less spherical) cluster. When applying the classical theory to such studies, the effect of ion size on the nucleation barrier must therefore be taken into account.

\subsection{Fitting procedure}

We ran the model of Merikanto et al. [2016] in the full three-dimensional parameter range for which we wished to create the parameterizations, for both neutral and the ion-induced cases. The neutral data was fitted using the same functional forms as the Vehkamäki et al. [2002] parameterization used, whereas for the ion-induced parameterization, the same principal form was chosen, but was optimized by adding or removing specific terms. The neutral parameterization follows the same logic as Vehkamäki et al. 
[2002] in that the fits for different parameters depend on each other, so they have to be used in a certain order. For the ion-induced parameterization the fitted quantities depend directly on the three varied parameters (temperature, relative humidity and sulfuric acid concentration). The fits were evaluated by using metrics such as R-squared $\left(\mathrm{R}^{2}\right)$ and root-mean-square error. All of the parameter fits for a particle formation pathway (i.e. neutral or ion-induced) were performed on the same set of data points, except for the neu-

tral threshold parameterization that required a high-resolution sulfuric acid concentration grid to find the points $\rho_{a}\left(J=1 \mathrm{~cm}^{-3} \mathrm{~s}^{-1}\right)$.

In the neutral case the theoretical dataset was calculated for a grid of $51 \times 54 \times 118$ points for temperature (linear grid from $150 \mathrm{~K}$ to $400 \mathrm{~K}$ with $\Delta T=5 \mathrm{~K}$ ), relative humidity (logarithmic grid from $10^{-5}$ to $100 \%$ ) and sulfuric acid concentration (logarithmic grid from $10^{4}$ to $10^{17} \mathrm{~cm}^{-3}$ ), respectively. In the ion-induced case the theoretical dataset was calculated for a grid of 51x72x118 points for temperature (linear grid from $150 \mathrm{~K}$ to 400 $\mathrm{K}$ with $\Delta T=5 \mathrm{~K}$ ), relative humidity (logarithmic grid from $10^{-6}$ to $100 \%$ ) and sulfuric acid concentration (logarithmic grid from $10^{4}$ to $10^{17} \mathrm{~cm}^{-3}$ ), respectively.

Additional limitations were imposed by two conditions: the lower limits for neutral particle formation rate $J>10^{-7} \mathrm{~cm}^{-3} \mathrm{~s}^{-1}$, ion-induced particle formation rate $J>10^{-10}$ $\mathrm{cm}^{-3} \mathrm{~s}^{-1}$ and number of sulfuric acid molecules in the critical cluster $n_{a}^{*}>1$ (kinetic limit). For ion-induced particle formation, the relative humidity range and the restriction on $J$ resulted in a lower temperature limit of $195 \mathrm{~K}$, whereas it is the kinetic limit $\left(n_{a}^{*}>1\right)$ that dictated the maximum sulfuric acid concentration. For neutral particle formation, the different limits were imposed in a similar manner. Additionally, in some cases the parameter space of the data was divided in several regions along one of the dimensions 
(for example, temperature or relative humidity) that were treated separately to ensure a good quality of the fits.

\section{Particle formation parameterizations}

Parameterizations are given for the neutral and ion-induced particle formation rates and the critical cluster sulfuric acid mole fraction, the critical cluster radius and the total number of molecules in the critical cluster. We also provide parameterizations for the limit at which particle formation becomes kinetic in both neutral and ion-induced cases, that is, the conditions where the free energy barrier limiting the particle formation rate disappears. Analytical equations are given for calculating the particle formation rate in the kinetic regime. Moreover, a parameterization for the threshold sulfuric acid concentration that yields a neutral particle formation rate of $1 \mathrm{~cm}^{-3} \mathrm{~s}^{-1}$ is given for three separate, but contiguous, temperature ranges (in the lowest temperature range particle formation is kinetic). The validity ranges cover the typical terrestrial parameter space as well as the conditions encountered in the cloud and haze formation region in the atmosphere of Venus.

\subsection{Neutral particle formation}

The validity of the neutral nucleation parameterization is limited to relative humidities from $0.001 \%$ to $100 \%$, sulfuric acid concentration from $10^{4}$ to $10^{13} \mathrm{~cm}^{-3}$, and to temperatures from 165 to $400 \mathrm{~K}$. The results of the parameterization are valid only if the resulting particle formation rate is $J>10^{-7} \mathrm{~cm}^{-3} \mathrm{~s}^{-1}$ and the number of sulfuric acid molecules in the critical cluster is $n_{a}^{*}>1$. The limit $n_{a}^{*}=1$ indicates that particle forma-

tion turns kinetic. We have developed another parameterization that gives the sulfuric 
acid concentration required for the kinetic limit as a function of relative humidity and temperature.

The mole fraction of sulfuric acid in the critical cluster, valid for both neutral and ion-induced case, is given by

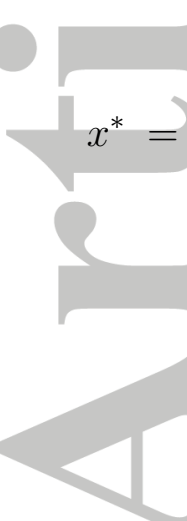

$$
+1.4976802556584141 \cdot 10^{-2} \ln \left(\rho_{a}\right)-2.4511581740839115 \cdot 10^{-4} T \ln \left(\rho_{a}\right)
$$$$
+3.4319869471066424 \cdot 10^{-3} \ln \left(\frac{R H}{100}\right)-2.8799393617748428 \cdot 10^{-5} T \ln \left(\frac{R H}{100}\right)
$$$$
+3.0174314126331765 \cdot 10^{-4}\left[\ln \left(\frac{R H}{100}\right)\right]^{2}-2.2673492408841294 \cdot 10^{-6} T\left[\ln \left(\frac{R H}{100}\right)\right]^{2}
$$$$
-4.3948464567032377 \cdot 10^{-3}\left[\ln \left(\frac{R H}{100}\right)\right]^{3}+5.3305314722492146 \cdot 10^{-5} T\left[\ln \left(\frac{R H}{100}\right)\right]^{3} \text {, }
$$

where $\rho_{a}$ is the total gas phase concentration of sulfuric acid $\left(1 / \mathrm{cm}^{3}\right), T$ is the absolute temperature and $R H$ is the relative humidity in \%.

The particle formation rate is given by an exponential of a third order polynomial of $\ln (R H / 100)$ and $\ln \left(\rho_{a}\right)$

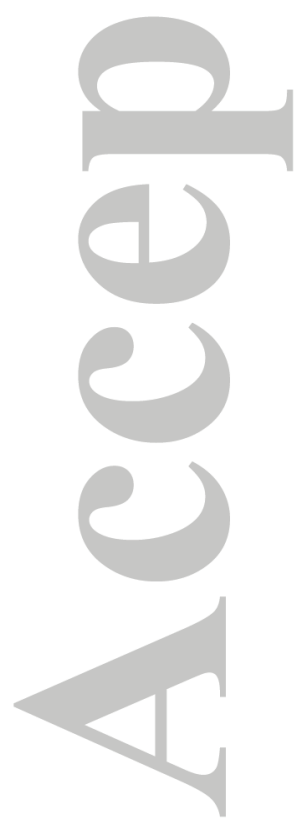


$J\left[1 /\left(\mathrm{cm}^{3} \mathrm{~s}\right)\right]=\exp \left\{g_{1}^{J}\left(T, x^{*}\right)\right.$

$$
\begin{aligned}
& +g_{2}^{J}\left(T, x^{*}\right) \ln (R H / 100)+g_{3}^{J}\left(T, x^{*}\right)[\ln (R H / 100)]^{2} \\
& +g_{4}^{J}\left(T, x^{*}\right)[\ln (R H / 100)]^{3}+g_{5}^{J}\left(T, x^{*}\right) \ln \left(\rho_{a}\right) \\
& +g_{6}^{J}\left(T, x^{*}\right) \ln (R H / 100) \ln \left(\rho_{a}\right) \\
& +g_{7}^{J}\left(T, x^{*}\right)[\ln (R H / 100)]^{2} \ln \left(\rho_{a}\right) \\
& +g_{8}^{J}\left(T, x^{*}\right)\left[\ln \left(\rho_{a}\right)\right]^{2} \\
& +g_{9}^{J}\left(T, x^{*}\right) \ln (R H / 100)\left[\ln \left(\rho_{a}\right)\right]^{2} \\
& \left.+g_{10}^{J}\left(T, x^{*}\right)\left[\ln \left(\rho_{a}\right)\right]^{3}\right\}
\end{aligned}
$$

where the coefficients $g_{N}^{J}\left(T, x^{*}\right)$ are functions of temperature and critical cluster mole fraction $x^{*}$ (calculated using equation (1)) of the following form:

$$
g_{N}^{J}\left(T, x^{*}\right)=d_{1, N}+d_{2, N} \cdot T+d_{3, N} \cdot T^{2}+d_{4, N} \cdot T^{3}+\frac{d_{5, N}}{x^{*}}
$$

The values of the coefficients $d_{1-5, N}$ of Eq. (3) are given in Table B2.

The total number of molecules in the critical cluster $n_{\mathrm{tot}}^{*}=n_{a}^{*}+n_{w}^{*}\left(\right.$ where $n_{a}^{*}$ and $n_{w}^{*}$ are the number of acid molecules and water molecules in the critical cluster, respectively)

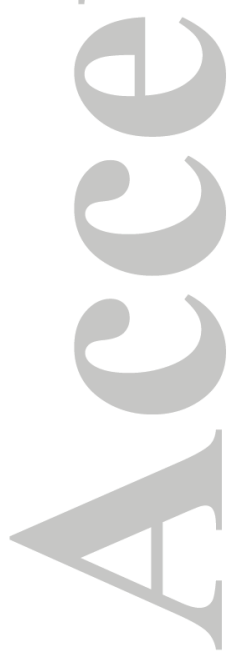


is given by

$$
n_{\text {tot }}^{*}=\exp \left\{G_{1}^{n}\left(T, x^{*}\right)\right.
$$

$$
\begin{aligned}
& +G_{2}^{n}\left(T, x^{*}\right) \ln (R H / 100)+G_{3}^{n}\left(T, x^{*}\right)[\ln (R H / 100)]^{2} \\
& +G_{4}^{n}\left(T, x^{*}\right)[\ln (R H / 100)]^{3}+G_{5}^{n}\left(T, x^{*}\right) \ln \left(\rho_{a}\right) \\
& +G_{6}^{n}\left(T, x^{*}\right) \ln (R H / 100) \ln \left(\rho_{a}\right) \\
& +G_{7}^{n}\left(T, x^{*}\right)[\ln (R H / 100)]^{2} \ln \left(\rho_{a}\right) \\
& +G_{8}^{n}\left(T, x^{*}\right)\left[\ln \left(\rho_{a}\right)\right]^{2} \\
& +G_{9}^{n}\left(T, x^{*}\right) \ln (R H / 100)\left[\ln \left(\rho_{a}\right)\right]^{2} \\
& \left.+G_{10}^{n}\left(T, x^{*}\right)\left[\ln \left(\rho_{a}\right)\right]^{3}\right\},
\end{aligned}
$$

where the coefficients $G_{N}^{n}\left(T, x^{*}\right)$ again depend on temperature and critical cluster mole fraction $x^{*}$ (from equation $\left.(1)\right)$ :

$$
G_{N}^{n}\left(T, x^{*}\right)=e_{1, N}+e_{2, N} \cdot T+e_{3, N} \cdot T^{2}+e_{4, N} \cdot T^{3}+\frac{e_{5, N}}{x^{*}}
$$

The values of the coefficients $e_{1-5, N}$ of Eq. (5) are given in Table B3.

The radius of the critical cluster is given as a function of the mole fraction and the total number of molecules in the cluster:

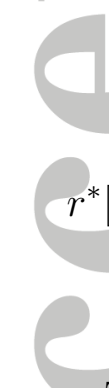

$$
r^{*}[\mathrm{~m}]=\exp \left[-22.378268374023630+0.44462953606125100 x^{*}+0.33499495707849131 \ln \left(n_{\mathrm{tot}}^{*}\right)\right] .
$$

The threshold total concentration of sulfuric acid for which particle formation rate is $J=1 \mathrm{~cm}^{-3} \mathrm{~s}^{-1}$ depends on the temperature and the relative humidity as given by the following equations. We divided the temperature range into three parts (155-185 K, (C)2017 American Geophysical Union. All Rights Reserved. 
where particle formation is in the kinetic range, $190-310 \mathrm{~K}$ and $310-400 \mathrm{~K}$ ) to ensure a good quality of the fits. The smallest RH used for fitting is $5 \%\left(S=5 \cdot 10^{-2}\right)$. We have included sulfuric acid concentrations above $10^{13} \mathrm{~cm}^{-3}$ (which were excluded from the parameterizations of $J, x^{*}, n_{\mathrm{tot}}^{*}$ and $r^{*}$ ) to enable the threshold parameterization to extend to the whole RH range also at high temperatures. For the (nucleation) range $310-400 \mathrm{~K}$ the threshold concentration parameterization is

$$
\begin{aligned}
& \rho_{a}^{J=1}\left[1 / \mathrm{cm}^{3}\right]=\exp \left[-2.8220714121794250+1.1492362322651116 \cdot 10^{1} \frac{R H}{100}\right. \\
& -\frac{3.3034839106184218 \cdot 10^{3}}{T}-\frac{7.1828571490168133 \cdot 10^{2}}{T} \frac{R H}{100}+1.4649510835204091 \cdot 10^{-1} T \\
& -3.0442736551916524 \cdot 10^{-2} \frac{R H}{100} T-9.3258567137451497 \cdot 10^{-5} T^{2} \\
& -1.1583992506895649 \cdot 10^{1} \ln \left(\frac{R H}{100}\right)+\frac{1.5184848765906165 \cdot 10^{3} \ln \left(\frac{R H}{100}\right)}{T} \\
& \left.+1.8144983916747057 \cdot 10^{-2} T \ln \left(\frac{R H}{100}\right)\right],
\end{aligned}
$$

and for the (nucleation) range 190-310 K:

$$
\begin{aligned}
& \rho_{a}^{J=1}\left[1 / \mathrm{cm}^{3}\right]=\exp \left[-3.1820396091231999 \cdot 10^{2}+7.2451289153199676 \frac{R H}{100}\right. \\
& +\frac{2.6729355170089486 \cdot 10^{4}}{T}-\frac{7.1492506076423069 \cdot 10^{2}}{T} \frac{R H}{100}+1.2617291148391978 T \\
& -1.6438112080468487 \cdot 10^{-2} \frac{R H}{100} T-1.4185518234553220 \cdot 10^{-3} T^{2} \\
& -9.2864597847386694 \ln \left(\frac{R H}{100}\right)+\frac{1.2607421852455602 \cdot 10^{3} \ln \left(\frac{R H}{100}\right)}{T} \\
& \left.+1.3324434472218746 \cdot 10^{-2} T \ln \left(\frac{R H}{100}\right)\right]
\end{aligned}
$$

For the range 155-185 K where particle formation is kinetic, the threshold concentration parameterization is:

$$
\begin{aligned}
\rho_{a}^{J=1}\left[1 / \mathrm{cm}^{3}\right] & =1.1788859232398459 \cdot 10^{5}-1.0244255702550814 \cdot 10^{4} \cdot \frac{R H}{100} \\
& +4.6815029684321962 \cdot 10^{3} \cdot\left(\frac{R H}{100}\right)^{2}-1.6755952338499657 \cdot 10^{2} \cdot T
\end{aligned}
$$


The following equation and the coefficients in Table B4 give the parameterization for the total concentration of sulfuric acid at the kinetic limit (as a function of $R H$ and $T$ ). Equation (10) should be used to check if the conditions are such that particle formation is kinetic, in which case the Eqs. (11) and (12) should be used to calculate the particle formation rate instead of Eq. (2). The kinetic limit sulfuric acid concentration (above which particle formation is kinetic) for the full $R H$ range is of the form:

$$
\begin{aligned}
& \rho_{a}^{\mathrm{kin}}\left[1 / \mathrm{cm}^{3}\right]=\exp \left[K_{1, N}+K_{2, N} \frac{R H}{100}+\frac{K_{3, N}}{T}+\frac{K_{4, N}}{T} \frac{R H}{100}+K_{5, N} T\right. \\
& \left.+K_{6, N} \frac{R H}{100} T+K_{7, N} T^{2}+K_{8, N} \ln \left(\frac{R H}{100}\right)+\frac{K_{9, N} \ln \left(\frac{R H}{100}\right)}{T}+K_{10, N} T \ln \left(\frac{R H}{100}\right)\right] .
\end{aligned}
$$

We have divided the relative humidity range in three parts $(R H=1 \%-100 \%, 0.01 \%-1 \%$ and $0.0005 \%-0.01 \%$ ) to ensure a good quality of the fits. The values of the coefficients $K_{1-10, N}$ of Eq. (10) for the three $R H$ ranges $\left(\mathrm{N}=1: R H=1 \%-100 \%, \mathrm{~N}=2: R H=0.01 \%^{-}\right.$ $1 \%, \mathrm{~N}=3: R H=0.0005 \%-0.01 \%$ ) are given in Table $\mathrm{B} 4$.

The neutral particle formation rate in the kinetic range $\left(J_{\text {kin }}\right)$ can be easily calculated via the following equations [Merikanto et al., 2016]:

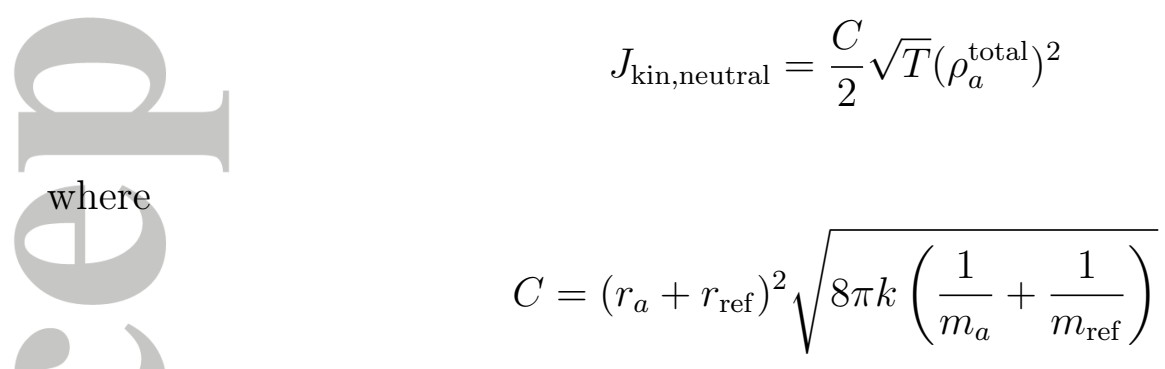

where $r_{\text {ref }}=r_{a}=0.3 \cdot 10^{-9} \mathrm{~m}$ and $m_{\text {ref }}=m_{a}=1.661 \cdot 10^{-27} \mathrm{~kg}$ in the neutral particle formation case.

\subsection{Ion-induced particle formation}

In the following we present the parameterizations for the ion-induced particle formation rate, the number of molecules in the critical cluster and the critical cluster radius as (C) 2017 American Geophysical Union. All Rights Reserved. 
functions of $\rho_{a}$, the total gas phase concentration of sulfuric acid $\left(\mathrm{cm}^{-3}\right), T$, the absolute temperature, and $R H$, the relative humidity in \%. The kinetic limit sulfuric acid concentration parameterization is given as a function of temperature $T$ and relative humidity $R H$. Note that the critical cluster mole fraction can be solved from Equation (1) for both neutral and ion-induced particle formation [see Eq. (6) of Merikanto et al., 2016, and the references therein].

The validity of the ion-induced nucleation parameterization is limited to relative humidities from $10^{-5 \%}$ to $100 \%$, sulfuric acid concentration from $10^{4}$ to $10^{16} \mathrm{~cm}^{-3}$, and the temperature range 195-400 K. The results of the parameterization are valid only if the resulting particle formation rate (assuming a negative ion concentration of $1 \mathrm{~cm}^{-3}$ ) is $J>10^{-10} \mathrm{~cm}^{-3} \mathrm{~s}^{-1}$ and total number of sulfuric acid molecules in the critical cluster is $n_{a}^{*}>1$, since at this limit particle formation becomes kinetic. This ion-induced kinetic limit is described by another parameterization. The ion-induced particle formation rate has to be multiplied by the actual negative ion concentration (typically some hundreds to some thousand negative ions $\mathrm{cm}^{-3}$ ) to get rates in the conditions investigated. Depending on the chemistry of the atmosphere studied, negative ion concentration can depend on the sulfuric acid concentration and vice versa. As the input values of our parameterization, these two concentrations are treated as independent variables, and the coupling between them in the studied case can be specified before calling the parametrization.

The ion-induced particle formation rate for the assumed negative ion concentration of 1 $\mathrm{cm}^{-3}$ is given by the following dependence on $\ln (R H / 100)$ and $\ln \left(\rho_{a}\right)$ (the actual particle formation rate is obtained by multiplying with the actual ion concentration in $\mathrm{cm}^{-3}$ ): 


$$
\begin{aligned}
J\left[1 /\left(\mathrm{cm}^{3} \mathrm{~s}\right)\right]= & \exp \left[f_{1}^{J}(T)+f_{2}^{J}(T) \cdot\left[\ln \left(\frac{R H}{100}\right)\right]^{-2}+f_{3}^{J}(T) \cdot\left[\ln \left(\frac{R H}{100}\right)\right]^{-2} \cdot \ln \rho_{a}\right. \\
& +f_{4}^{J}(T) \cdot\left[\ln \left(\frac{R H}{100}\right)\right]^{-1} \cdot \ln ^{-1} \rho_{a}+f_{5}^{J}(T) \cdot\left[\ln \left(\frac{R H}{100}\right)\right]^{-1} \\
& +f_{6}^{J}(T) \cdot\left[\ln \left(\frac{R H}{100}\right)\right]^{-1} \cdot \ln \rho_{a}+f_{7}^{J}(T) \cdot\left[\ln \left(\frac{R H}{100}\right)\right]^{-1} \cdot \ln ^{2} \rho_{a} \\
& +f_{8}^{J}(T) \cdot\left[\ln \left(\frac{R H}{100}\right)\right]^{-1} \cdot \ln ^{3} \rho_{a}+f_{9}^{J}(T) \cdot \ln { }^{-2} \rho_{a}+f_{10}^{J}(T) \cdot \ln ^{-1} \rho_{a} \\
& +f_{11}^{J}(T) \cdot \ln \rho_{a}+f_{12}^{J}(T) \cdot \ln ^{2} \rho_{a}+f_{13}^{J}(T) \cdot \ln ^{3} \rho_{a} \\
& +f_{14}^{J}(T) \cdot \ln \left(\frac{R H}{100}\right) \cdot \ln ^{-2} \rho_{a}+f_{15}^{J}(T) \cdot \ln \left(\frac{R H}{100}\right) \cdot \ln ^{-1} \rho_{a} \\
& +f_{16}^{J}(T) \cdot \ln \left(\frac{R H}{100}\right)+f_{17}^{J}(T) \cdot \ln \left(\frac{R H}{100}\right) \cdot \ln \rho_{a}+f_{18}^{J}(T) \cdot \ln \left(\frac{R H}{100}\right) \cdot \ln ^{2} \rho_{a} \\
& +f_{19}^{J}(T) \cdot \ln \left(\frac{R H}{100}\right) \cdot \ln ^{3} \rho_{a}+f_{20}^{J}(T) \cdot\left[\ln \left(\frac{R H}{100}\right)\right]^{2} \cdot \ln ^{-1} \rho_{a} \\
& +f_{21}^{J}(T) \cdot\left[\ln \left(\frac{R H}{100}\right)\right]^{2}+f_{22}^{J}(T) \cdot\left[\ln \left(\frac{R H}{100}\right)\right]^{2} \cdot \ln \rho_{a} \\
& \left.+f_{23}^{J}(T) \cdot\left[\ln \left(\frac{R H}{100}\right)\right]^{2} \cdot \ln ^{2} \rho_{a}+f_{24}^{J}(T) \cdot \frac{R H}{100}\right] \\
&
\end{aligned}
$$

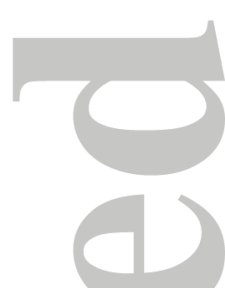

where the coefficients $f_{N}^{J}$ are functions of temperature $T$ as follows:

$$
f_{N}^{J}(T)=a_{1, N}+a_{2, N} \cdot T+a_{3, N} \cdot T^{2}+a_{4, N} \cdot T^{3}+a_{5, N} \cdot T^{-1},
$$

and the coefficients $a_{1-5, N}$ for each $f_{N}^{J}(T)$ are given in Table B5.

(C)2017 American Geophysical Union. All Rights Reserved. 
The number of molecules in the critical cluster in the ion-induced case can be calculated as a function of $\ln (R H / 100)$ and $\ln \left(\rho_{a}\right)$ with the following expression:

$$
\begin{aligned}
n_{\mathrm{tot}}^{*}= & \left(f_{1}^{n}(T)+f_{2}^{n}(T) \cdot\left[\ln \left(\frac{R H}{100}\right)\right]^{-2} \cdot \ln ^{-2} \rho_{a}+f_{3}^{n}(T) \cdot\left[\ln \left(\frac{R H}{100}\right)\right]^{-2}\right. \\
& +f_{4}^{n}(T) \cdot\left[\ln \left(\frac{R H}{100}\right)\right]^{-2} \cdot \ln \rho_{a}+f_{5}^{n}(T) \cdot\left[\ln \left(\frac{R H}{100}\right)\right]^{-1} \cdot \ln ^{-2} \rho_{a} \\
+ & f_{6}^{n}(T) \cdot\left[\ln \left(\frac{R H}{100}\right)\right]^{-1} \cdot \ln ^{-1} \rho_{a}+f_{7}^{n}(T) \cdot\left[\ln \left(\frac{R H}{100}\right)\right]^{-1} \\
& +f_{8}^{n}(T) \cdot\left[\ln \left(\frac{R H}{100}\right)\right]^{-1} \cdot \ln \rho_{a}+f_{9}^{n}(T) \cdot \ln ^{-2} \rho_{a}+f_{10}^{n}(T) \cdot \ln ^{-1} \rho_{a} \\
& +f_{11}^{n}(T) \cdot \ln \rho_{a}+f_{12}^{n}(T) \cdot \ln ^{2} \rho_{a}+f_{13}^{n}(T) \cdot \ln \left(\frac{R H}{100}\right) \cdot \ln ^{-2} \rho_{a} \\
& +f_{14}^{n}(T) \cdot \ln \left(\frac{R H}{100}\right) \cdot \ln ^{-1} \rho_{a}+f_{15}^{n}(T) \cdot \ln \left(\frac{R H}{100}\right)+f_{16}^{n}(T) \cdot \ln \left(\frac{R H}{100}\right) \cdot \ln \rho_{a} \\
& +f_{17}^{n}(T) \cdot\left[\ln \left(\frac{R H}{100}\right)\right]^{2}+f_{18}^{n}(T) \cdot\left[\ln \left(\frac{R H}{100}\right)\right]^{2} \cdot \ln ^{-1} \rho_{a}+f_{19}^{n}(T) \cdot\left[\ln \left(\frac{R H}{100}\right)\right]^{-3} \\
& \left.+f_{20}^{n}(T) \cdot \frac{R H}{100} \cdot \ln \rho_{a}+f_{21}^{n}(T) \cdot \frac{R H}{100}+f_{22}^{n}(T) \cdot \frac{R H}{100} \cdot \ln ^{2} \rho_{a}\right) \mid
\end{aligned}
$$

where the coefficients $f_{N}^{n}$ are functions of temperature $T$ as follows:

$$
f_{N}^{n}(T)=b_{1, N}+b_{2, N} \cdot T+b_{3, N} \cdot T^{2}+b_{4, N} \cdot T^{-1}+b_{5, N} \cdot T^{3}
$$

and the coefficients $b_{1-5, N}$ for each $f_{N}^{n}(T)$ are given in Table B6. 
The critical cluster radius for ion-induced particle formation can be evaluated using the following expression:

$$
\begin{aligned}
r^{*}[\mathrm{~m}]= & f_{1}^{r}(T)+f_{2}^{r}(T) \cdot\left[\ln \left(\frac{R H}{100}\right)\right]^{-2} \cdot \ln ^{-1} \rho_{a}+f_{3}^{r}(T) \cdot\left[\ln \left(\frac{R H}{100}\right)\right]^{-2} \\
& +f_{4}^{r}(T) \cdot\left[\ln \left(\frac{R H}{100}\right)\right]^{-2} \cdot \ln \rho_{a}+f_{5}^{r}(T) \cdot\left[\ln \left(\frac{R H}{100}\right)\right]^{-1} \cdot \ln ^{-2} \rho_{a} \\
& +f_{6}^{r}(T) \cdot\left[\ln \left(\frac{R H}{100}\right)\right]^{-1} \cdot \ln ^{-1} \rho_{a}+f_{7}^{r}(T) \cdot\left[\ln \left(\frac{R H}{100}\right)\right]^{-1} \\
& +f_{8}^{r}(T) \cdot\left[\ln \left(\frac{R H}{100}\right)\right]^{-1} \cdot \ln \rho_{a}+f_{9}^{r}(T) \cdot\left[\ln \left(\frac{R H}{100}\right)\right]^{-1} \cdot \ln ^{2} \rho_{a} \\
& +f_{10}^{r}(T) \cdot \ln -2 \frac{\rho_{a}}{}+f_{11}^{r}(T) \cdot \ln { }^{-1} \rho_{a}+f_{12}^{r}(T) \cdot \ln \rho_{a}+f_{13}^{r}(T) \cdot \ln ^{2} \rho_{a} \\
& +f_{14}^{r}(T) \cdot \ln \left(\frac{R H}{100}\right) \cdot \ln ^{-2} \rho_{a}+f_{15}^{r}(T) \cdot \ln \left(\frac{R H}{100}\right) \cdot \ln { }^{-1} \rho_{a} \\
& +f_{16}^{r}(T) \cdot \ln \left(\frac{R H}{100}\right)+f_{17}^{r}(T) \cdot \ln \left(\frac{R H}{100}\right) \cdot \ln \rho_{a}+f_{18}^{r}(T) \cdot \ln \left(\frac{R H}{100}\right) \cdot \ln ^{2} \rho_{a} \\
& +f_{19}^{r}(T) \cdot\left[\ln \left(\frac{R H}{100}\right)\right]^{2} \cdot \ln { }^{-1} \rho_{a}+f_{20}^{r}(T) \cdot\left[\ln \left(\frac{R H}{100}\right)\right]^{2} \\
& +f_{21}^{r}(T) \cdot\left[\ln \left(\frac{R H}{100}\right)\right]^{2} \cdot \ln \rho_{a}+f_{22}^{r}(T) \cdot\left[\ln \left(\frac{R H}{100}\right)\right]^{3} \cdot \ln \rho_{a}
\end{aligned}
$$

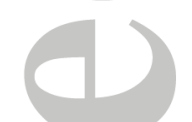

where the coefficients $f_{N}^{r}$ are functions of temperature $T$ as follows:

$$
f_{N}^{r}(T)=c_{1, N}+c_{2, N} \cdot T+c_{3, N} \cdot T^{2}+c_{4, N} \cdot T^{3}
$$

and the coefficients $c_{1-4, N}$ for each $f_{N}^{r}(T)$ are given in Table B7. 
The sulfuric acid threshold concentration for kinetic ion-induced particle formation can be expressed as a function of temperature and relative humidity as

$$
\ln \rho_{a}^{\mathrm{kin}}\left[\mathrm{cm}^{-3}\right]=L_{1}+L_{2} \cdot\left[\ln \left(\frac{R H}{100}\right)\right]^{-2}+L_{3} \cdot\left[\ln \left(\frac{R H}{100}\right)\right]^{-1}+L_{4} \cdot \ln \left(\frac{R H}{100}\right)
$$

$$
\begin{aligned}
& -L_{5} \cdot\left[\ln \left(\frac{R H}{100}\right)\right]^{2}+L_{6} \cdot\left[\ln \left(\frac{R H}{100}\right)\right]^{3}+L_{7} \cdot\left[\ln \left(\frac{R H}{100}\right)\right]^{4} \\
& +L_{8} \cdot T \cdot\left[\ln \left(\frac{R H}{100}\right)\right]^{-2}+L_{9} \cdot T \cdot\left[\ln \left(\frac{R H}{100}\right)\right]^{-1}+L_{10} \cdot T \cdot \ln \left(\frac{R H}{100}\right)
\end{aligned}
$$$$
+L_{11} \cdot T \cdot\left[\ln \left(\frac{R H}{100}\right)\right]^{2}+L_{12} \cdot T \cdot\left[\ln \left(\frac{R H}{100}\right)\right]^{3}
$$$$
+L_{13} \cdot T \cdot\left[\ln \left(\frac{R H}{100}\right)\right]^{4}+L_{14} \cdot T^{2} \cdot\left[\ln \left(\frac{R H}{100}\right)\right]^{-1}
$$$$
+L_{15} \cdot T^{2} \cdot \ln \left(\frac{R H}{100}\right)+L_{16} \cdot T^{2} \cdot\left[\ln \left(\frac{R H}{100}\right)\right]^{2}
$$$$
+L_{17} \cdot T^{2} \cdot\left[\ln \left(\frac{R H}{100}\right)\right]^{3}+L_{18} \cdot T^{3} \cdot\left[\ln \left(\frac{R H}{100}\right)\right]^{-1}
$$$$
+L_{19} \cdot T^{3} \cdot \ln \left(\frac{R H}{100}\right)+L_{20} \cdot T^{3} \cdot\left[\ln \left(\frac{R H}{100}\right)\right]^{2}
$$$$
+L_{21} \cdot T^{-1}+L_{22} \cdot T+L_{23} \cdot T^{2}+L_{24} \cdot T^{3} \text {. }
$$

The coefficients $L_{N}$ are given in Table B8.

In the kinetic range the ion-induced particle formation can be described with the following equation [Merikanto et al., 2016]:

$$
J_{\text {kin,ion-induced }}=C \rho_{\text {pre }} \sqrt{T}\left(\rho_{a}^{\text {total }}\right)
$$

where $C$ is given as in Eq. 12 with $r_{\text {ref }}=r_{\text {ion }}=0.487 \cdot 10^{-9} \mathrm{~m}$ and $m_{\text {ref }}=m_{\text {ion }}=$

$1.661 \cdot 10^{-27} \mathrm{~kg}$, and the pre-existing cluster concentration $\rho_{\text {pre }}$ is simply the negative ion concentration $\rho_{\text {ion }}$.

\subsection{How to apply the parameterizations in practice?}

The particle formation calculations using the parameterizations are computationally orders of magnitude more efficient than with the full theory, and hence the parameterizations 
are suitable for large scale atmospheric models. A Fortran code for the parameterizations is included in the supplementary electronic material. When using the parameterizations in, for example, a microphysical/atmospheric model, it is advisable to use the same thermodynamical data (density, surface tension, activities, etc., see Merikanto et al. [2016]) as used here for consistency. It should also be noted that double precision for floats should be used to avoid possibly large deviations from the expected behavior.

1. The total particle formation rate is the sum of the neutral and the ion-induced rates: $J_{\text {tot }}=J_{\text {neutral }}+J_{\text {ion }}$

2. The ion-induced formation rate is limited by the ion pair production rate $q$ : $J_{\text {ion }}=$ $\min \left(J_{\text {ion }}, q\right)$. This condition should be taken into account if the ion concentration is used as an input value for the parameterization. However, one can also solve the steady state ion concentration from the equation [Dunne et al., 2016]

$$
\rho_{\text {ion }}=\frac{\sqrt{\left(X^{2}+4 \alpha q\right)}-X}{2 \alpha},
$$

where $\alpha$ is the recombination coefficient and $\mathrm{X}$ is the linear loss rate of ions via nucleation itself and due to coagulational scavenging onto pre-existing particles,

$$
X=\operatorname{CoagS}+\frac{\mathrm{J}_{\text {ion }}}{\rho_{\text {ion }}},
$$

where CoagS is the coagulation sink for the ions. When the ion production rate, the coagulation sink, and the recombination rate are provided as inputs, the ion-induced nucleation rate automatically saturates to the ion pair production rate when nucleation itself dominates the losses of ions. This calculation is included into the provided Fortran

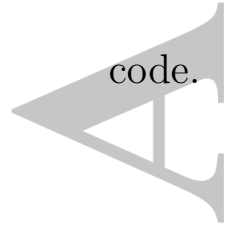

(C)2017 American Geophysical Union. All Rights Reserved. 
3. The ion-induced particle formation rate is directly proportional to the ion concentration: $J_{\text {ion }} \propto \rho_{\text {ion }}$. The parameterization has been calculated for $\rho_{\text {ion }}=1 \mathrm{~cm}^{-3}$ and should be scaled accordingly (as is done in the provided Fortran code).

4. The particle formation rates are calculated at the (critical) formation size. If the parameterizations are used compared to measurements at larger sizes or in an atmospheric model where the smallest size bin is larger than the formation size, the formation rates at those sizes should be evaluated using formulations developed for this purpose [Kerminen and Kulmala, 2002; Lehtinen et al., 2007; Duplissy et al., 2016]. For example, to calculate the formation rates at the size of $3 \mathrm{~nm}: J_{3 \mathrm{~nm}}=J_{\text {neutral }} \cdot K K\left(r_{\text {neutral }}\right)+J_{\text {ion }} \cdot K K\left(r_{\text {ion }}\right)$, where $K K$ is the scaling given by, for example, Kerminen and Kulmala [2002] or Lehtinen et al. [2007]. The supplied Fortran code includes the Lehtinen et al. [2007] scaling.

Finally, a quick review of the different parameterizations is given in Table B1.

\section{Results}

In this section, we compare the new parameterized particle formation rates and cluster properties in a wide range of conditions against the new theoretical ones [Merikanto et al., 2016], and against the old parameterization and theory [Vehkamäki et al., 2002]. It should be noted that, as in Vehkamäki et al. [2002], the low temperature results are based on extrapolations of the thermodynamic parameters below $230 \mathrm{~K}$.

\subsection{Neutral parameterization}

The four panels of Figure 1 show a comparison of the theoretical and the parametrized values for the particle formation rate, the sulfuric acid mole fraction, the total number of molecules and the radius of the critical cluster.

(C)2017 American Geophysical Union. All Rights Reserved. 
The ratio of the theoretical and the parameterized particle formation rates (top left panel of Fig. 1) shows that in the whole range of particle formation rates most of the cases are within one order of magnitude $\left(10^{-1}-10^{1}\right)$ of the perfect fit. Our wider ranges for all the input variables cause larger deviations between the theoretical values and the fit than in the parametrization of Vehkamäki et al. [2002]. For very low and very high theoretical particle formation rates the parameterization may overestimate the rates by a factor of $10^{3}$ in some cases. These cases are related to the extremities of the validity ranges. For example, for high sulfuric acid concentrations (above $10^{9} \mathrm{~cm}^{-3}$ ) sometimes the model predicts very large clusters ( $n_{\text {tot }}^{*}$ around 100) with corresponding very low particle formation rates, which are overestimated by the parameterization. This overestimation grows with growing sulfuric acid concentration and is particularly clear for concentrations above approximately $10^{11} \mathrm{~cm}^{-3}$, giving the highest overestimations of small particle formation rates (cases on the left extremity of Fig. for $\mathrm{J}_{\text {theoretical }} / \mathrm{J}_{\text {param }}$ values below $10^{-2}$ ). However, the largest discrepancies between the theoretical and the parameterized particle formation rates are either at insignificantly low particle formation rates, where the particle formation is practically zero, or at extremely high particle formation rates where particle formation rate is not the limiting factor for appearance of particles of atmospheric relevance, but also growth and loss processes play a major role.

The top right panel of Figure 1 shows the difference between the theoretical and parameterized mole fractions. Fractions below $x^{*}<0.5$ are best fitted (difference between theory and parameterization ranging between -0.017 and 0.007$)$, but above this value the difference grows. In particular, the mole fractions above $x^{*}>0.7$ are somewhat overestimated (deviation up to 0.069 ) by the parameterization. The relative errors are at most 
around $13 \%$ (lowest mole fractions) and stay below $9 \%$ at high mole fractions. The best fits are acquired in the range $x^{*}=0.33-0.45$ (relative errors around or less than $1 \%$ ). The difference between the theoretical and the parameterized total number of molecules in the critical cluster seen in the bottom left panel of Fig. 1 shows that the best fit is achieved for small $n_{\text {tot }}^{*}$, with larger absolute deviations appearing the larger the $n_{\text {tot }}^{*}$ is. The values of $n_{\mathrm{tot}}^{*}$ vary from 1 to 200, with large total numbers corresponding to very small particle formation rates, lower limit being $\mathrm{J}=10^{-7} \mathrm{~cm}^{-3} \mathrm{~s}^{-1}$. The deviations range between -3 and +5 molecules at $n_{\text {tot }}^{*}=40$ and $n_{\text {tot }}^{*}=55$, respectively, giving a relative error of less than $10 \%$.

The critical cluster radii vary approximately between $0.28 \mathrm{~nm}$ and $1.2 \mathrm{~nm}$ (the bottom right panel of Fig. 1) with the ratio of the theoretical and the parameterized radii ranging between 0.98 and 1.07 .

It can be seen in Fig. 1 that the critical cluster radius parameterization catches very well the theoretical behavior, whereas the other parameterizations deviate more from theory. In fact, the critical cluster radius is much less sensitive to variations in environmental parameters, particularly saturation ratios, than the critical cluster mole fraction, the number of molecules in the critical cluster and the particle formation rate. The latter have a much stronger dependence on saturation ratios, and are thus much harder to fit with polynomial functions, leading to the larger deviations from theory.

Figure 2 shows the behavior of the particle formation rate for several sulfuric acid concentrations as a function of temperature and relative humidity. It can be seen that the difference between the Vehkamäki et al. [2002] model (crosses) and parameterization (dashed lines) and the present model (triangles) and parameterization (solid lines) is 
largest at low temperatures and at low relative humidities. The particle formation rates given by the old and the new model are nearly superposed above 230-250 K and above $\mathrm{RH}=1 \%$ of relative humidity (see the lowest four panels of Fig. 2), but differences are seen already at $270 \mathrm{~K}$ and $240 \mathrm{~K}$ when $\mathrm{RH}<1 \%$, depending also on the acid concentration. The largest differences between the present and Vehkamäki et al. [2002] results are seen at low acid concentrations (top panels in Fig. 2). The old parameterization is not valid below 190K (absence of dashed lines). The difference between the old and new models is also large at low relative humidities $\mathrm{RH}<1 \%$, depending on the acid concentration. Similarly, in the upper left panel of Fig. 2 the particle formation rates are seen to differ most below $210 \mathrm{~K}$ and particularly so for low relative humidities. Figure 2 demonstrates the good quality of our new parameterization, since the solid lines (the parameterized particle formation rates) are well superposed with the triangles representing the theoretical results. Comparison of the dashed and solid lines in the plots also reveals the larger validity range of the new parameterization. Note in particular the kinetic range (black lines and triangles), now accessible with our new parameterization. A slight discontinuity can be seen in the upper right panel at $175 \mathrm{~K}$, with the parameterization (solid lines) exhibiting a dip just before arriving at the kinetic limit. This is due to difficulties in fitting the functional form of the parameterization at the edge of the validity range.

Figures 3 and 4 show the behavior of the threshold concentration parameterization. The ratio of the theoretical to the parameterized values for the sulfuric acid concentration corresponding to particle formation rate $1 \mathrm{~cm}^{-3} \mathrm{~s}^{-1}$ is $0.99-1.01$ in the temperature range 155-185 K (kinetic range), 0.92-1.16 in the range 190-310 $\mathrm{K}$ and $0.83-1.13$ in the range 310-400 K. It can be seen that at all but the lowest temperatures the required sulfuric 
acid concentration decreases with decreasing temperature, as expected. For a given acid concentration, the saturation vapor pressure decreases and thus the saturation ratio increases with decreasing temperature. This leads to a lower particle formation barrier, and a larger value for the exponential term in the particle formation rate equation. At the same time the particle formation kinetics slows down, but the growth of the exponential term dominates. However, we can see that this is valid only down to temperature of 190 K (see Fig. 4), around which the kinetic regime is entered. Below this, the necessary acid concentration starts to increase with decreasing temperature. This can be explained by the vanishing particle formation barrier, leaving the kinetics as the determining factor. Since the kinetic processes slow down with decreasing temperature, a higher acid concentration will be required to maintain the same particle formation rate. This behavior was not seen in Vehkamäki et al. [2002], since in that work critical cluster sizes were limited to $n_{\text {tot }}^{*}>4$, whereas we go down to $n_{\text {tot }}^{*}>1$, and also model specifically the kinetic range. Note that in Fig. 4 the data points behave in a step-like manner only because of the coarse resolution of the sulfuric acid concentration grid.

The kinetic limit is described as the threshold sulfuric acid concentration above which particle formation is kinetic at a certain relative humidity and temperature. This concentration is lowest at low temperatures: for example, it is between $10^{0}$ and $10^{4} \mathrm{~cm}^{-3}$ at 160 $\mathrm{K}$. The variation of the threshold concentration for a constant temperature arises from the RH-dependence, giving the lowest threshold at highest $\mathrm{RH}$. The threshold concentration reaches $10^{18} \mathrm{~cm}^{-3}$ at $400 \mathrm{~K}$. The fit for the sulfuric acid concentration at the kinetic limit is within $10-12 \%$ of the theoretical results. Note that $\mathrm{RH}=0 \%$ cannot be used because the fitting function contains logarithms of RH. 


\subsection{Ion-induced parameterization}

Figure 5 shows a comparison of the theoretical and the parametrized values for the particle formation rate, the total number of molecules and the radius of the critical cluster in the ion-induced case.

The top panel of Fig. 5 reveals that in general the parameterization describes well the ion-induced particle formation rate, but seems to overestimate the rate in particular at the lowest and the highest theoretical formation rates. Mostly the parameterized rates are within two orders of magnitude of the perfect fit with some excursions up to 3-4 orders of magnitude (largest overestimation by the parameterization being a factor of $3 \cdot 10^{4}$ and largest underestimation a factor of $\left.1 / 8 \cdot 10^{2}\right)$.

The parameterization for the number of molecules in the critical cluster (middle panel of Fig. 5) overestimates the values at most by about $40 \%$ and underestimates the values by almost $50 \%$ in the smallest cluster sizes in some isolated cases, but overall the differences are small.

The critical radius parameterization behaves well (the bottom panel of Fig. 5) with slight overestimations of the radius at smallest sizes and underestimation at the largest sizes. The maximum deviations remain below $8 \%$.

The parameterization for the sulfuric acid concentration at the kinetic limit is within $15 \%$ of the perfect fit most of the time, with highest values at the lowest and highest threshold concentration values. Naturally, as in the neutral case, the kinetic limit sulfuric acid concentration increases with increasing temperature and with decreasing relative humidity: the concentration is the highest at high temperatures and low relative humidi-

ties. The kinetic limit sulfuric acid concentration spans a large range from $10^{-10} \mathrm{~cm}^{-3}$ 
at $\mathrm{T}=160 \mathrm{~K}$ and $\mathrm{RH}=100 \%$ to $10^{16} \mathrm{~cm}^{-3}$ at $\mathrm{T}=400 \mathrm{~K}$ and $\mathrm{RH}=0.1 \%$. The kinetic limit concentrations are always significantly lower than the corresponding values for the neutral case.

Figure 6 shows a detailed comparison between the theoretical ion-induced particle formation rates (symbols) and the parameterized ones (lines). The kinetic range is shown in black. The choice of the ion concentration $\mathrm{N}_{\text {ion }}=4000 \mathrm{~cm}^{-3}$ in Fig. 6 is arbitrary, representing the higher end of the observed atmospheric negative small ion concentrations [Hirsikko et al., 2011] and corresponds to typical conditions with the Pion beam turned on in the CLOUD experiments [Duplissy et al., 2016]. In Venus, Michael et al. [2009] predicted similar concentrations of around $N_{\text {ion }}=3000 \mathrm{~cm}^{-3}$ (their Fig. 17) in the cloud region at 50-60 km altitude. The ion-induced nucleation rate parameterization (solid lines) follows the theory well (triangles). The temperature at which the kinetic ioninduced range (black solid lines and triangles) is reached increases with increasing sulfuric acid concentration and increasing relative humidity, similarly as in the neutral case.

\subsection{Comparison with Dunne et al. [2016] parameterization}

Recently, Dunne et al. [2016] published a state-of-the-art aerosol formation parameterization based on CLOUD measurements. Because the experiments had a very limited RH-range, their two-component parameterization does not include the relative humidity dependence of particle formation. The parameterizations in this paper are based on a state-of-the-art model, allowing us to use it confidently also outside the experimental ranges of the parameters, and our parameterization includes the relative humidity dependence. The difference between the measured particle formation rates and those given by the Dunne et al. [2016] parameterization can be several orders of magnitude, as seen in 
the Supplementary Figure S6 of Dunne et al. [2016]. We present a comparison of the two ion-induced parameterizations and CLOUD data in Figure 7.

\subsection{Implementation in a global model}

To test the parameterization in realistic atmospheric modeling conditions, we have implemented the new particle formation parameterizations in the global aerosol-climate model ECHAM5.5-HAM2 [Stier et al., 2005; Zhang et al., 2012]. This model describes the aerosol population with four soluble and three insoluble log-normal modes, including sulfate, organic carbon, black carbon, dust and sea salt. The simulations are performed

in T63 resolution with 31 vertical levels, and the model is nudged against ERA-Interim meteorology of the year 2000, and the results are averaged over one year after a 6-month spin-up period. The simulations include anthropogenic aerosol and precursor emissions from ACCMIP [Lamarque et al., 2010], while sea salt, dust and DMS emissions are calculated online. We test four parameterization schemes using the global model 1) Vehkamäki et al. [2002] binary nucleation parameterization, 2) Kazil et al. [2010]; Kazil and Lovejoy [2007] neutral and ion-induced parameterization, 3) new parameterization with only neutral pathway, and 4) new parameterization including neutral and ion-induced pathways. The ion-pair production rates are based on Kazil et al. [2010], and nucleation rates are converted to $3 \mathrm{~nm}$ formation rates using Kerminen and Kulmala [2002] as described in Makkonen et al. [2009]. There are no additional nucleation mechanisms active in the four scenarios.

Figure 8 a shows a comparison of total particle concentration $(\mathrm{CN})$ in the four global simulations with the ECHAM5.5-HAM2 model. The simulation with both neutral and ion-induced pathways indicates that, averaging globally, ion-induced nucleation increases 
the total aerosol concentration about $20 \%$ between surface and $600 \mathrm{hPa}$. Around 300-400 hPa, the ion pathway makes only a small contribution to the total nucleation rates. The total concentrations from simulations using Kazil et al. [2010] are higher than with the new neutral parameterization, but generally lower than with the new parameterization including both nucleation pathways.

The new neutral parameterization produces a typical zonal pattern (Fig. 8b) with high average nucleation rates of $10-100 \mathrm{~cm}^{-3} \mathrm{~s}^{-1}$ in the UTLS (Upper Troposhere and Lower Stratosphere) and generally low rates in the lower atmosphere, in agreement with earlier studies [Makkonen et al., 2009; Yu et al., 2010; Lee et al., 2013]. The ion pathway (Fig. 8c) results in a vertically smoother profile and lower absolute rates above $400 \mathrm{hPa}$ level, but clearly exceeds the neutral nucleation rates in the lower troposphere. The effect of ion-induced nucleation is indeed clearly visible in the difference plot of total particle concentration (Fig. 8d): simulations with IIN show clearly increased concentrations especially between 500-800 hPa at midlatitudes and even closer to the surface at high latitudes. The slight decrease in concentration around $300 \mathrm{hPa}$ is likely due to aerosol microphysical feedbacks where higher nucleation rates below $500 \mathrm{hPa}$ lead to a slight decrease in nucleation rates higher up in the atmosphere.

\subsection{Implications for Venus cloud modeling}

All of the Venus cloud models published so far use somewhat generic condensation nuclei with activation at saturation [James et al., 1997; Imamura and Hashimoto, 2002; McGouldrick and Toon, 2007; Gao et al., 2014] or simply prescribed particle production rates [Yamamoto and Takahashi, 2006], which also provide an easy means to tune the resulting cloud properties. Because of insufficient parameter ranges of Vehkamäki et al. 
[2002]; Vehkamäki et al. [2003], homogeneous particle formation on Venus has not been modeled yet. It cannot be excluded either, since no measurements have shed light on the existence of the potential condensation nuclei, and the conditions on Venus potentially enable the homogeneous pathway. In addition, studies on the ionization of the atmosphere [Michael et al., 2009; Nordheim et al., 2015; Plainaki et al., 2016] suggest that atmospheric ions could be present in sufficient quantities (some thousands of ions per cubic centimeter at the cloud level) for the ion-induced particle formation pathway to be active. In the following we present some results for the atmospheric parameter ranges encountered in the Venus cloud layers.

The results in Figures 9 and 10 show that the new parameterizations capture well the Venus-relevant range of parameters. At low relative humidity conditions $(\mathrm{RH}<1 \%)$ and the range of $\left[\mathrm{H}_{2} \mathrm{SO}_{4}\right]$ encountered within the Venus clouds $\left(10^{7}-10^{13} \mathrm{~cm}^{-3}\right)$, and average ion concentrations of $4000 \mathrm{~cm}^{-3}$, particle formation occurs only at or below $300 \mathrm{~K}$. Particle formation is kinetic in most cases with very low RH. It can also be seen that at high sulfuric acid concentrations the neutral parameterization follows very well the theoretical rates in the neutral case, and the deviations of several orders of magnitude seen in the upper left panel of Fig. 1 are not a concern in the Venus conditions. For the ion-induced parameterization the deviations from theoretical values at low $\mathrm{RH}$ are significant for the very low formation rates (see also the top panel of Fig. 5).

Looking at the upper left panel of the Figure 9, we can see that in the conditions of the upper cloud of Venus $\left(\left[\mathrm{H}_{2} \mathrm{SO}_{4}\right]=10^{7} \mathrm{~cm}^{-3}, \mathrm{RH}=0.03 \%, \mathrm{~T}=230 \mathrm{~K}\right)$, homogeneous particle formation rates are very low, at the limit of the validity range of our parameterization $\left(J>10^{-7} \mathrm{~cm}^{-3} \mathrm{~s}^{-1}\right)$. With slightly higher $\mathrm{RH}(0.1-1 \%)$ the formation rates become higher, 
and with a higher sulfuric acid concentration $\left(10^{10} \mathrm{~cm}^{-3}\right)$ the rates for low RH become significant $\left(10^{10} \mathrm{~s}^{-1} \mathrm{~cm}^{-3}\right)$ around the temperature of $230 \mathrm{~K}$ (middle left panel of the Figure 9). The conclusions are similar for the ion-induced case (upper and middle panels of the Figure 10), with a drastic transition from nearly insignificant formation rates at lower sulfuric acid concentrations (Fig. 10, upper panels) to significant kinetic particle formation at slightly higher sulfuric acid concentrations (Fig. 10, middle panels).

For the lower Venus cloud conditions (lower panels of the Figure 9, $\left[\mathrm{H}_{2} \mathrm{SO}_{4}\right]=10^{13} \mathrm{~cm}^{-3}$, $\mathrm{RH}=0.003 \%, \mathrm{~T}>350 \mathrm{~K})$ it seems that neutral homogeneous particle formation can be excluded. Higher relative humidities or lower temperatures would be required for particle formation to happen at these sulfuric acid concentrations. The same conclusion holds for the ion-induced particle formation pathway (lower panels of the Figure 10). It should be noted that the lower clouds of Venus are probably the end result of condensational growth of particles formed at higher altitudes and thus they should be close to thermodynamic equilibrium. The zone is very turbulent, which enables the vapors evaporated from droplets that have fallen in the sub-saturated zone below the cloud to be injected back to the lower cloud. The re-injected vapors condense on the existing cloud droplets that function as a very efficient condensation sink. Thus formation of new particles at this zone might not be likely in any case.

A full investigation of the intensities of particle formation pathways on Venus is left for a future study.

\section{Conclusions}

We have developed new parameterizations based on an improved model [Merikanto et al., 2016] for particle formation of sulfuric acid and water in the neutral and ion-induced 
cases. The new neutral parameterization widens the validity range of the Vehkamäki et al. [2002] and Vehkamäki et al. [2003] parameterizations to lower relative humidities and higher sulfuric acid concentrations, and to a larger temperature range. Parameterizations are given for particle formation rate $\left(J>10^{-7} \mathrm{~cm}^{-3} \mathrm{~s}^{-1}\right)$, radius and composition of the critical cluster, and number of molecules $\left(n_{\mathrm{tot}}^{*}>1\right)$ in the critical cluster as functions of temperature and relative humidity. We have also parameterized the sulfuric acid concen-

trations yielding formation rate $1 / \mathrm{cm}^{3} \mathrm{~s}$ and the sulfuric acid concentration above which particle formation is a barrierless kinetic process. In the kinetic regime, a simple analytic formula can be used for the formation rate.

The neutral parameterization for the formation rate $J$ deviates slightly more from the theoretical values than the one of Vehkamäki et al. [2002] but the largest discrepancies are found at very high or very low particle formation rates with little relevance for correctly predicting whether particle formation is occurring or not. The other parametrized quantities follow the theoretical predictions well with errors mostly below $10 \%$ (12\% at maximum). The new theory and the new parameterization differ the most from the ones of Vehkamäki et al. [2002] at low temperatures and relative humidities, and at low acid concentrations.

The ion-induced parameterization behaves overall as well as the neutral one, with the parameterization overestimating the particle formation rates by $3-4$ orders of magnitude at very low and high theoretical formation rates. For the critical cluster radius the relative differences are always below $8 \%$, but for the number of molecules in the critical cluster the differences can reach almost $50 \%$. The kinetic limit is well described by the parameterization, the relative difference being always below $15 \%$.

(C)2017 American Geophysical Union. All Rights Reserved. 
The parameterizations presented here account for the relative humidity dependence of particle formation, whereas those of Dunne et al. [2016] do not. Our parameterizations can also be used confidently outside the CLOUD measurement range since they are based on a solid state-of-the-art theory and model, which is validated by CLOUD measurements. Implementing the new parameterizations in a global model shows similar trends as produced by previous parameterizations, but including the ion-induced pathway increases the particle formation rates clearly in the lower troposphere at mid- and high latitudes (aerosol concentrations higher by $20 \%$ compared to the neutral pathway only). Higher up in the atmosphere the ion-induced contribution is smaller.

Our results show that in the conditions prevailing within the Venus cloud layers homogeneous and ion-induced nucleation pathways are possible in the upper and middle cloud, but formation rates are very sensitive to fluctuations in vapor concentrations and temperature. In the average lower cloud conditions neither of the pathways is efficient enough: the microphysical processes in this zone create a very strong condensation sink probably excluding new particle formation.

We recommend using the new model and the improved parameterizations from now on instead of Vehkamäki et al. [2002] and Vehkamäki et al. [2003]. The model reproduces results of state-of-the-art particle formation measurements well [Duplissy et al., 2016]. The neutral parameterization widens the validity range of the Vehkamäki et al. [2002] and Vehkamäki et al. [2003] parameterizations, approaches correctly the one-component limit and the kinetic limit. A new ion-induced parameterization has been produced for a large range of conditions. This development opens new opportunities for Terrestrial

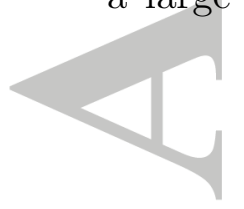

(C)2017 American Geophysical Union. All Rights Reserved. 
atmosphere studies, and the Venus cloud community can use the new parameterization in the range of conditions encountered within the Venus cloud formation region.

Fortran code containing the parameterizations (DOI: 10.5281/zenodo.1044366)

is given in the Supplementary Material and can be downloaded from Zenodo (https://doi.org/10.5281/zenodo.1044366).

\section{Appendix A: Behavior of the two-component nucleation theory at the one-}

\section{component limit}

When starting to develop the new parameterization, we were particularly interested in very low relative humidities, and preliminary calculations revealed the formation of near-pure sulfuric acid clusters $(x \geq 0.99)$ in these conditions. Thus we have performed both theoretical and numerical tests to ensure the correct behavior of the two-component particle formation model at the one-component limit.

The general expression for the nucleation rate $J$ is

$$
J=\frac{\left|\lambda_{1}\right|}{2 \pi k T} \rho^{*} \frac{1}{\sqrt{\left|\operatorname{det} \frac{W^{*}}{2 \pi k T}\right|}},
$$

where $\rho^{*}$ is the number concentration of critical clusters in the vapor phase. When using a self-consistent cluster distribution the concentration $\rho^{*}$ is known to reduce correctly to the one-component case at the one-component limit [Wilemski and Wyslouzil, 1995], but the behavior of the kinetic term $\left|\lambda_{1}\right| / \sqrt{\left|\operatorname{det} W^{*}\right|}$ needs to be examined, where $\left|\lambda_{1}\right|$ is the negative eigenvalue of the product matrix $R^{*} W^{*}$. The matrix $R^{*}$ contains the condensation coefficients that describe the collisions of clusters of size $n_{a}, n_{w}$ with the

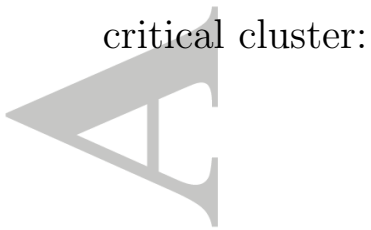




$$
\begin{gathered}
R_{a a}^{*}=\sum_{n_{a}=1, n_{w}=0}^{N_{c}} n_{a}^{2}\left(r^{*}+r\right)^{2} \sqrt{8 \pi k T\left(\frac{1}{m^{*}}+\frac{1}{m}\right)} \rho\left(n_{a}, n_{w}\right) \\
R_{w w}^{*}=\sum_{n_{a}=0, n_{w}=1}^{N_{c}} n_{w}^{2}\left(r^{*}+r\right)^{2} \sqrt{8 \pi k T\left(\frac{1}{m^{*}}+\frac{1}{m}\right)} \rho\left(n_{a}, n_{w}\right) \\
R_{a w}^{*}=R_{w a}^{*}=\sum_{n_{a}=1, n_{w}=1}^{N_{c}} n_{a} n_{w}\left(r^{*}+r\right)^{2} \sqrt{8 \pi k T\left(\frac{1}{m^{*}}+\frac{1}{m}\right)} \rho\left(n_{a}, n_{w}\right),
\end{gathered}
$$

where $N_{c}$ stands for the largest hydrate accounted for. The matrix $W^{*}$ contains the second derivatives of the formation energy with respect to the number of molecules in the cluster $\left(W_{a a}, W_{a w}, W_{w w}\right)$, which can be written as follows:

$$
\begin{gathered}
W_{a a} \equiv \frac{d^{2} \Delta \varphi}{d n_{a}^{2}}=\frac{-v_{a}\left(x^{*}\right)^{2} \sigma}{2 \pi r^{* 4}}+\left(k T \frac{d \mathcal{A}_{a}}{d x_{a}} \frac{1}{\mathcal{A}_{a}}+2 \frac{d v_{a}\left(x^{*}\right)}{d x_{a}} \frac{\sigma}{r^{*}}+2 v_{a}\left(x^{*}\right) \frac{d \sigma}{d x_{a}} \frac{1}{r^{*}}\right) \frac{n_{w}^{*}}{\left(n_{a}^{*}+n_{w}^{*}\right)^{2}} \\
W_{w w} \equiv \frac{d^{2} \Delta \varphi}{d n_{w}^{2}}=\frac{-v_{w}\left(x^{*}\right)^{2} \sigma}{2 \pi r^{* 4}}+\left(k T \frac{d \mathcal{A}_{w}}{d x_{w}} \frac{1}{\mathcal{A}_{w}}+2 \frac{d v_{w}\left(x^{*}\right)}{d x_{w}} \frac{\sigma}{r^{*}}+2 v_{w}\left(x^{*}\right) \frac{d \sigma}{d x_{w}} \frac{1}{r^{*}}\right) \frac{n_{a}^{*}}{\left(n_{a}^{*}+n_{w}^{*}\right)^{2}} \\
W_{a w}=W_{w a} \equiv \frac{d^{2} \Delta \varphi}{d n_{w} d n_{a}}=\frac{-v_{a}\left(x^{*}\right) v_{w}\left(x^{*}\right) \sigma}{2 \pi r^{* 4}}+\left(k T \frac{d \mathcal{A}_{w}}{d x_{w}} \frac{1}{\mathcal{A}_{w}}+2 \frac{d v_{w}\left(x^{*}\right)}{d x_{w}} \frac{\sigma}{r^{*}}\right. \\
\left.+2 v_{w}\left(x^{*}\right) \frac{d \sigma}{d x_{w}} \frac{1}{r^{*}}\right) \frac{n_{w}^{*}}{\left(n_{a}^{*}+n_{w}^{*}\right)^{2}}
\end{gathered}
$$

where $\mathcal{A}_{a}$ and $\mathcal{A}_{w}$ are, respectively, the gas phase activities of acid and water.

Here $\rho\left(n_{a}, n_{w}\right)$ is the concentration of clusters containing $n_{a}$ sulfuric acid molecules and $n_{w}$ water molecules, $m^{*}$ and $r^{*}$ are the mass and the radius of the critical cluster, and $m$ and $r$ are the mass and the radius of the cluster colliding with the critical cluster.

The eigenvalues $\lambda_{1,2}$ of the product matrix $R^{*} W^{*}$

$$
\left(\begin{array}{ll}
R_{w w} & R_{w a} \\
R_{a w} & R_{a a}
\end{array}\right)\left(\begin{array}{ll}
W_{w w} & W_{w a} \\
W_{a w} & W_{a a}
\end{array}\right)
$$


where we use the shorthand notation $\alpha=W_{w w} R_{w w}+W_{a a} R_{a a}+2 W_{w a} R_{w a}$. When the concentration of sulfuric acid, $\rho_{a}=\rho(1,0)$, is much higher than that of water, $\rho_{w}=\rho(0,1)$ (i.e., $\rho_{a}>>\rho_{w}$ ), the cluster consists almost solely of sulfuric acid, $x \geq 0.99$. The formation free energy surface around the critical cluster area forms a steep valley with almost vertical walls and the bottom of the valley running along the $n_{a}$-axis. When moving across the valley on a line parallel to the $n_{w}$-axis, the slope of the free energy surface changes fast from a large negative number to a large positive number when passing the critical size. Thus, the magnitude of the second derivate $\left|W_{w w}\right|$ is large, approaching infinity for a truly one-component system. When moving along the bottom of the valley up to the critical size and down after that, the slope changes less rapidly, $\left|W_{w w}\right|>>\left|W_{a a}\right|$. Also, when comparing the almost infinite slopes in the $n_{w}$ direction for different values of $n_{a}$, it can be concluded that these slopes do not depend strongly on the location along the $n_{a}$-axis, and thus $\left|W_{w a}\right|$ has modest values and $\left|W_{w w}\right|>>\left|W_{w a}\right|$. The condensation coefficient $R_{a a}$ contains terms representing the collisions of the critical cluster with small clusters with acid only, as well as those with both acid and water. If there is much more acid than water molecules in the system, the acid-only-clusters dominate over the clusters with both acid and water molecules as well as over clusters with only water molecules. The coefficient $R_{w w}$ contains terms representing the collisions of the critical cluster with water clusters only and water-acid clusters, and the coefficient $R_{a w}$ contains terms representing only water-acid clusters, and thus it can be concluded that for the nearly pure acid case $R_{a a}>R_{w a}, R_{a a}>>R_{w w}$

In this case the determinants of the matrices can be approximated as $\operatorname{det} W=$ $W_{w w} W_{a a}-W_{w a}^{2} \approx W_{w w} W_{a a}$ and $\operatorname{det} R=R_{w w} R_{a a}-R_{w a}^{2} \approx R_{w w} R_{a a}$. The parameter $\alpha \operatorname{can}$ 
be written as $\alpha=R_{w w}\left(W_{w w}+R_{a a} / R_{w w} \cdot W_{a a}+2 R_{w a} / R_{w w} \cdot W_{w a}\right) \approx W_{w w} R_{w w}+W_{a a} R_{a a}$. This is justified as $R_{w a}$ and $R_{w w}$ contain almost similar terms apart from the term proportional to $\rho(0,1)=\rho_{w}$, which is very small compared to the terms corresponding to clusters with acid molecules in them. Another difference between $R_{w a}$ and $R_{w w}$ is the multiplication of the terms with $n_{a} n_{w}$ vs. multiplication with $n_{w}^{2}$, but this does not change the order of magnitude of the summation results. Thus $R_{w a} / R_{w w}$ is of the order of 1 , and $\left|W_{w a}\right|$ is small compared to $\left|W_{w w}\right|$, whereas $R_{a a} / R_{w w}$ is large and thus $R_{a a} / R_{w w} \cdot W_{a a}$ cannot safely be neglected although $\left|W_{w w}\right|>>\left|W_{a a}\right|$.

Inserting these approximations into Eq. (A9) we get an approximate expression for the eigenvalues:

$$
\lambda_{1,2} \approx \frac{1}{2}\left[W_{w w} R_{w w}+W_{a a} R_{a a} \pm\left(W_{w w} R_{w w}-W_{a a} R_{a a}\right)\right]
$$

This results in simple expressions for the two eigenvalues of the product matrix $R^{*} W^{*}$

$$
\lambda_{1,2}=\left\{\begin{array}{l}
W_{a a} R_{a a}<0 \\
W_{w w} R_{w w}>0 .
\end{array}\right.
$$

and we can evaluate the term $\left|\lambda_{1}\right| / \sqrt{\left|\operatorname{det} W^{*}\right|}$ of the nucleation rate equation (A1):

$$
\frac{\left|\lambda_{1}\right|}{\sqrt{\left|\operatorname{det} W^{*}\right|}} \approx \frac{-W_{a a} R_{a a}}{\sqrt{\left|W_{w w} W_{a a}\right|}}=R_{a a} \sqrt{\frac{\left|W_{a a}\right|}{W_{w w}}} .
$$

In the cases of two-component nucleation at the one-component limit we thus get:

$$
J_{2-\text { comp }}^{1-\text { limit }}=R_{a a} \sqrt{\frac{\left|W_{a a}^{2-\text { comp }}\right|}{W_{w w}^{2-\text { comp }}}} \rho^{*}
$$

since the $2 \pi k T$ terms in equation (A1) cancel in the two-component case. The standard one-component Zeldovich factor reads [Vehkamäki, 2006]

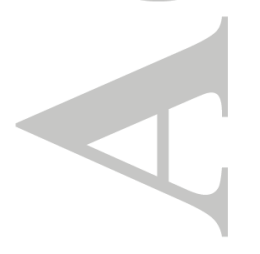

$$
J_{1-\mathrm{comp}}=R_{a a} \sqrt{\frac{\left|W_{a a}^{1-\mathrm{comp}}\right|}{2 \pi k T}} \rho^{*},
$$


It can now be seen that

$$
\frac{J_{2-\text { comp }}^{1-\text { limit }}}{J_{1-\text { comp }}}=\sqrt{\frac{2 \pi k T}{W_{w w}}} \sqrt{\frac{W_{a a}^{2-\text { comp }}}{W_{a a}^{1-\text { comp }}}},
$$

which indicates that the presence of water affects the nucleation rate even when approaching the only-acid limit.

This can be understood as follows: For numerical reasons the sulfuric acid mole fraction in the critical cluster cannot be set to exactly one (in our study we used $x=0.99$ at most), and as a consequence, water has necessarily a role in the process. Mathematically, in the hypothetical case of $x=1$, some elements of matrices $R^{*}$ and $W^{*}$ would be zero or infinite and these matrices would thus be ill-behaved. In CNT the main contribution to the nucleation rate comes from the net flow of clusters through the critical cluster size in the direction of the eigenvector corresponding to the negative eigenvalue $\lambda_{1}$. The cluster flows on paths parallel to this main path, passing by the critical cluster size, are however taken into account by integrating over all these secondary paths giving rise to a factor $\sqrt{\left(2 \pi k T / W_{w w}\right)}$ seen in Eq. (A15). As the second derivative $W_{w w}$ does not approach $2 \pi k T$ even though $\rho_{a}>>\rho_{w}$, this factor does not reduce to unity at the one-component limit. It must also be noted that because water concentration cannot be equal to zero in the two-component theory, the second derivative $W_{a a}$ does not exactly have its one-component value $v_{a}^{2} \sigma_{a} /\left(2 \pi r^{* 4}\right)$ either.

\section{Appendix B: Data related to the parameterized fits}

A Fortran code containing the parameterizations (DOI: 10.5281/zenodo.1044366) is included in the supplementary electronic material and at https://doi.org/10.5281/zenodo.1044366.

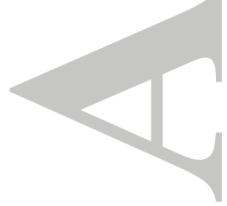

(C)2017 American Geophysical Union. All Rights Reserved. 
Acknowledgments. Fortran code containing the parameterizations (DOI: 10.5281/zenodo.1044366) is given in the Supplementary Material and can be found at https://doi.org/10.5281/zenodo.1044366. The datasets used for developing the parameterizations and the global model outputs used for producing the Figure 8 (DOI: 10.5281/zenodo.1098190) can be found at https://doi.org/10.5281/zenodo.1098190. We thank the Editor and the anonymous reviewers for their very constructive and helpful comments. We acknowledge the contribution of J. Julin for fitting the parameterization for the neutral particle formation and the expertise of Theo Kurtén on atmospheric ions. We are grateful for the Institut Pierre Simon Laplace (IPSL) Solar System Group that funded a one-week visit of Prof. Vehkamäki at the IPSL. We also acknowledge the ERC Starting MOCAPAF grant no. 257360, the Agence national de la recherche (ANR, project Exoclimats) and the Programme national de planétologie for funding and support. JM acknowledges Academy of Finland for funding (project 287440). JM and AM received a travel grant from the Magnus Ehrnrooth foundation that helped immensely in finalizing this article. The EU FP7 BACCHUS project (grant agreement 603445) and Nordic Center of Excellence eSTICC (Nordforsk grant 57001) are acknowledged for financial support. We thank CSC-IT Center for Science in Espoo, Finland, for computing time. We acknowledge the CLOUD collaboration at CERN for their ground-breaking nucleation experiments.

\section{References}

Bauer, S. E., D. L. Wright, D. Koch, E. R. Lewis, R. McGraw, L.-S. Chang, S. E. Schwartz, and R. Ruedy (2008), MATRIX (Multiconfiguration Aerosol TRacker of mIXing state): 
an aerosol microphysical module for global atmospheric models, Atmospheric Chemistry and Physics, 8(20), 6003-6035, doi:10.5194/acp-8-6003-2008.

Beig, G., and G. Brasseur (2000), Model of tropospheric ion composition: A first attempt, J. Geophys. Res., 105, 22,67122,684, doi:10.1029/2000JD900119.

Binder, K., and D. Stauffer (1976), Statistical theory of nucleation, condensation and coagulation, Adv. Phys., 25, 343-396.

Boucher, O., D. Randall, P. Artaxo, C. Bretherton, G. Feingold, P. Forster, V.-M. Kerminen, Y. Kondo, H. Liao, U. Lohmann, P. Rasch, S. Satheesh, S. Sherwood, B. Stevens, and X. Zhang (2013), Climate Change 2013: The Physical Science Basis. Contribution of Working Group I to the Fifth Assessment Report of the Intergovernmental Panel on Climate Change, chap. Clouds and Aerosols, Cambridge University Press, Cambridge, United Kingdom and New York, NY, USA.

Donald, W. A., and E. R. Williams (2008), Evaluation of different implementations of the Thomson liquid drop model: Comparison to monovalent and divalent cluster ion experimental data, The Journal of Physical Chemistry A, 112(16), 3515-3522, doi: 10.1021/jp711012b, pMID: 18358015.

Donald, W. A., R. D. Leib, M. Demireva, B. Negru, D. M. Neumark, and E. R. Williams (2011), Average sequential water molecule binding enthalpies of $\mathrm{M}\left(\mathrm{H}_{2} \mathrm{O}\right)_{19-124^{2+}}(\mathrm{M}=$ Co, Fe, Mn, and $\mathrm{Cu}$ ) measured with ultraviolet photodissociation at 193 and $248 \mathrm{~nm}$, The Journal of Physical Chemistry A, 115(1), 2-12, doi:10.1021/jp107547r.

Doyle, G. J. (1961), Self-Nucleation in the Sulfuric Acid-Water System, J. Chem. Phys., 35, 795-799, doi:10.1063/1.1701218. 
Dunne, E. M., H. Gordon, A. Kürten, J. Almeida, J. Duplissy, C. Williamson, I. K. Ortega, K. J. Pringle, A. Adamov, U. Baltensperger, P. Barmet, F. Benduhn, F. Bianchi, M. Breitenlechner, A. Clarke, J. Curtius, J. Dommen, N. M. Donahue, S. Ehrhart, R. C. Flagan, A. Franchin, R. Guida, J. Hakala, A. Hansel, M. Heinritzi, T. Jokinen, J. Kangasluoma, J. Kirkby, M. Kulmala, A. Kupc, M. J. Lawler, K. Lehtipalo, V. Makhmutov,

G. Mann, S. Mathot, J. Merikanto, P. Miettinen, A. Nenes, A. Onnela, A. Rap, C. L. S. Reddington, F. Riccobono, N. A. D. Richards, M. P. Rissanen, L. Rondo, N. Sarnela, S. Schobesberger, K. Sengupta, M. Simon, M. Sipilä, J. N. Smith, Y. Stozkhov, A. Tomé, J. Tröstl, P. E. Wagner, D. Wimmer, P. M. Winkler, D. R. Worsnop, and K. S. Carslaw (2016), Global atmospheric particle formation from CERN CLOUD measurements, Science, 354 (6316), 1119-1124, doi:10.1126/science.aaf2649.

Duplissy, J., J. Merikanto, A. Franchin, G. Tsagkogeorgas, J. Kangasluoma, D. Wimmer, H. Vuollekoski, S. Schobesberger, K. Lehtipalo, R. Flagan, D. Brus, N. Donahue, H. Vehkamäki, J. Almeida, A. Amorim, P. Barmet, F. Bianchi, M. Breitenlechner, E. Dunne, R. Guida, H. Henschel, H. Junninen, J. Kirkby, A. Kürten, A. Kupc, A. Määttänen, V. Makhmutov, S. Mathot, T. Nieminen, A. Onnela, A. Praplan, F. Riccobono, L. Rondo, G. Steiner, A. Tome, H. Walther, U. Baltensperger, K. Carslaw, J. Dommen, A. Hansel, T. Petäjä, M. Sipilä, F. Stratmann, A. Vrtala, P. Wagner, D. Worsnop, J. Curtius, and M. Kulmala (2016), Effect of ions on sulfuric acid-water binary particle formation ii: Experimental data and comparison with qc-normalized classical nucleation theory, J. Geophys. Res., pp. 1752-1775, doi:10.1002/2015JD023539, 2015JD023539.

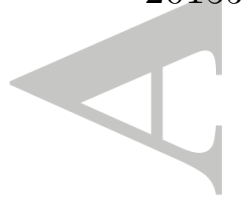


Ehn, M., H. Junninen, T. Petäjä, T. Kurtén, V.-M. Kerminen, S. Schobesberger, H. E. Manninen, I. K. Ortega, H. Vehkamäki, M. Kulmala, and D. R. Worsnop (2010), Composition and temporal behavior of ambient ions in the boreal forest, Atmos. Chem. Phys., 10, 8513-8530.

Esposito, L. W., R. G. Knollenberg, M. I. Marov, O. B. Toon, and R. P. Turco (1983), The clouds and hazes of Venus, in Venus, edited by D. M. Hunten, L. Colin, T. M. Donahue, and V. I. Moroz, pp. 484-564, University of Arizona Press.

Gao, P., X. Zhang, D. Crisp, C. G. Bardeen, and Y. L. Yung (2014), Bimodal distribution of sulfuric acid aerosols in the upper haze of Venus, Icarus, 231, 83-98, doi: 10.1016/j.icarus.2013.10.013.

Henschel, H., J. C. A. Navarro, T. Yli-Juuti, O. Kupiainen-Määttä, T. Olenius, I. K. O. Colomer, S. L. Clegg, T. Kurtén, I. Riipinen, and H. Vehkamäki (2014), Hydration of atmospherically relevant molecular clusters: Computational chemistry and classical thermodynamics, J. Phys. Chem. A, 118, 25992611.

Hirsikko, A., T. Nieminen, S. Gagné, K. Lehtipalo, H. E. Manninen, M. Ehn, U. Horrak, V.-M. Kerminen, L. Laakso, P. H. McMurry, A. Mirme, S. Mirme, T. Petäjä, H. Tammet, V. Vakkari, M. Vana, and M. Kulmala (2011), Atmospheric ions and nucleation: a review of observations, Atmos. Chem. Phys., 11, 767798.

Hofmann, D., J. Barnes, M. O’Neill, M. Trudeau, and R. Neely (2009), Increase in background stratospheric aerosol observed with lidar at Mauna Loa Observatory and Boulder, Colorado, Geophys. Res. Lett., 36, L15808, doi:10.1029/2009GL039008.

Hommel, R., C. Timmreck, M. A. Giorgetta, and H. F. Graf (2015), Quasi-biennial oscillation of the tropical stratospheric aerosol layer, Atmospheric Chemistry and Physics, 
$15(10), 5557-5584$, doi:10.5194/acp-15-5557-2015.

Imamura, T., and G. L. Hashimoto (2002), $\mathrm{H}_{2} \mathrm{SO}_{4}$ cycle in the Venusian tropical atmosphere as constrained by a microphysical cloud model, Advances in Space Research, 29, 249 -254, doi:10.1016/S0273-1177(01)00575-0.

James, E. P., O. B. Toon, and G. Schubert (1997), A numerical microphysical model of the condensational Venus cloud, Icarus, 129, 147-171.

Kazil, J., and E. R. Lovejoy (2007), A semi-analytical method for calculating rates of new sulfate aerosol formation from the gas phase, Atmospheric Chemistry and Physics, 7 , $3447-3459$.

Kazil, J., P. Stier, K. Zhang, J. Quaas, S. Kinne, D. O’Donnell, S. Rast, M. Esch, S. Ferrachat, U. Lohmann, and J. Feichter (2010), Aerosol nucleation and its role for clouds and Earth's radiative forcing in the aerosol-climate model echam5-ham, Atmospheric Chemistry and Physics, $10(22)$, 10,733-10,752, doi:10.5194/acp-10-10733-2010.

Kerminen, V.-M., and M. Kulmala (2002), Analytical formulae connecting the "real" and the "apparent" nucleation rate and the nuclei number concentration for atmospheric nucleation events, Journal of Aerosol Science, 33, 609-622.

Kirkby, J., J. Curtius, J. Almeida, E. Dunne, J. Duplissy, S. Ehrhart, A. Franchin, S. Gagné, L. Ickes, A. Kürten, A. Kupc, A. Metzger, F. Riccobono, L. Rondo, S. Schobesberger, G. Tsagkogeorgas, D. Wimmer, A. Amorim, F. Bianchi, M. Breitenlechner, A. David, J. Dommen, A. Downard, M. Ehn, R. C. Flagan, S. Haider, A. Hansel, D. Hauser, W. Jud, H. Junninen, F. Kreissl, A. Kvashin, A. Laaksonen, K. Lehtipalo, J. Lima, E. R. Lovejoy, V. Makhmutov, S. Mathot, J. Mikkilä, P. Minginette, S. Mogo, T. Nieminen, A. Onnela, P. Pereira, T. Petäjä, R. Schnitzhofer, J. H. Seinfeld, 
M. Sipilä, Y. Stozhkov, F. Stratmann, A. Tomé, J. Vanhanen, Y. Viisanen, A. Vrtala, P. E. Wagner, H. Walther, E. Weingartner, H. Wex, P. M. Winkler, K. S. Carslaw, D. R. Worsnop, U. Baltensperger, and M. Kulmala (2011), Role of sulphuric acid, ammonia and galactic cosmic rays in atmospheric aerosol nucleation, Nature, 476, 429-433, doi:10.1038/nature10343.

Korhonen, H., K. E. J. Lehtinen, and M. Kulmala (2004), Multicomponent aerosol dynamics model UHMA: model development and validation, Atmospheric Chemistry and Physics Discussions, 4, 471-506.

Krasnopolsky, V., and F. Lefèvre (2013), Comparative Climatology of Terrestrial Planets, chap. Chemistry of the atmospheres of Mars, Venus and Titan, pp. 231-275, Univ. of Arizona, Tucson.

Kuang, C., P. H. McMurry, A. V. McCormick, and F. L. Eisele (2008), Dependence of nucleation rates on sulfuric acid vapor concentration in diverse atmospheric locations, Journal of Geophysical Research (Atmospheres), 113, D10209, doi: 10.1029/2007JD009253.

Kulmala, M., A. Laaksonen, and L. Pirjola (1998), Parametrizations for sulfuric acid/water nucleation rates, J. Geophys. Res., 103, 8301-8308.

Kurtén, T., M. Noppel, H. Vehkamäki, M. Salonen, and M. Kulmala (2007), Quantum chemical studies of hydrate formation of $\mathrm{H}_{2} \mathrm{SO}_{4}$ and $\mathrm{HSO}_{4}^{-}$, Boreal Environment Research, 12, 431-453.

Lamarque, J.-F., T. C. Bond, V. Eyring, C. Granier, A. Heil, Z. Klimont, D. Lee, C. Liousse, A. Mieville, B. Owen, M. G. Schultz, D. Shindell, S. J. Smith, E. Stehfest, J. Van Aardenne, O. R. Cooper, M. Kainuma, N. Mahowald, J. R. McConnell, V. Naik, 
K. Riahi, and D. P. van Vuuren (2010), Historical (1850-2000) gridded anthropogenic and biomass burning emissions of reactive gases and aerosols: methodology and application, Atmos. Chem. Phys., 10(15), 7017-7039, doi:10.5194/acp-10-7017-2010.

Lee, S.-H., J. M. Reeves, J. C. Wilson, D. E. Hunton, A. A. Viggiano, T. M. Miller, J. O. Ballenthin, and L. R. Lait (2003), Particle Formation by Ion Nucleation in the Upper Troposphere and Lower Stratosphere, Science, 301, 1886-1889, doi: 10.1126/science.1087236.

Lee, Y. H., J. R. Pierce, and P. J. Adams (2013), Representation of nucleation mode microphysics in a global aerosol model with sectional microphysics, Geoscientific Model Development, 6, 1221-1232, doi:10.5194/gmd-6-1221-2013.

Lehtinen, K. E. J., M. Dal Maso, M. Kulmala, and V.-M. Kerminen (2007), Estimating nucleation rates from apparent particle formation rates and vice versa: Revised formulation of the Kerminen-Kulmala equation, Journal of Aerosol Science, 38, 988-994.

Makkonen, R., A. Asmi, H. Korhonen, H. Kokkola, S. Järvenoja, P. Räisänen, K. E. J. Lehtinen, A. Laaksonen, V.-M. Kerminen, H. Järvinen, U. Lohmann, R. Bennartz, J. Feichter, and M. Kulmala (2009), Sensitivity of aerosol concentrations and cloud properties to nucleation and secondary organic distribution in ECHAM5-HAM global circulation model, Atmospheric Chemistry \& Physics, 9, 1747-1766.

McGouldrick, K., and O. B. Toon (2007), An investigation of possible causes of the holes in the condensational Venus cloud using a microphysical cloud model with a radiativedynamical feedback, Icarus, 191, 1-24, doi:10.1016/j.icarus.2007.04.007.

McGouldrick, K., O. B. Toon, and D. H. Grinspoon (2011), Sulfuric acid aerosols in the atmospheres of the terrestrial planets, Planet. Space Sci., 59, 934-941, doi: 
10.1016/j.pss.2010.05.020.

Merikanto, J., D. V. Spracklen, G. W. Mann, S. J. Pickering, and K. S. Carslaw (2009), Impact of nucleation on global CCN, Atmos. Chem. Phys., 9, 8601-8616.

Merikanto, J., J. Duplissy, A. Määttänen, H. Henschel, N. M. Donahue, D. Brus, S. Schobesberger, M. Kulmala, and H. Vehkamäki (2016), Effect of ions on sulfuric acid-water binary particle formation I: Theory for kinetic and nucleation-type particle formation and atmospheric implications, J. Geophys. Res., 121, 1736-1751, doi: 10.1002/2015JD023539.

Michael, M., S. N. Tripathi, W. J. Borucki, and R. C. Whitten (2009), Highly charged cloud particles in the atmosphere of Venus, Journal of Geophysical Research: Planets, 114 (E4), n/a-n/a, doi:10.1029/2008JE003258, e04008.

Modgil, M. S., S. Kumar, S. N. Tripathi, and E. R. Lovejoy (2005), A parameterization of ion-induced nucleation of sulphuric acid and water for atmospheric conditions, $J$. Geophys. Res., 110, D19,205.

Noppel, M., H. Vehkamäki, and M. Kulmala (2002), An improved model for hydrate formation in sulfuric-acid water nucleation, J. Chem. Phys, 116, 218-228.

Nordheim, T., L. Dartnell, L. Desorgher, A. Coates, and G. Jones (2015), Ionization of the venusian atmosphere from solar and galactic cosmic rays, Icarus, 245 (Supplement C), 80 - 86, doi:https://doi.org/10.1016/j.icarus.2014.09.032.

Ortega, I. K., O. Kupiainen, T. Kurtén, T. Olenius, O. Wilkman, M. J. McGrath, V. Loukonen, and H. Vehkamäki (2012), From quantum chemical formation free energies to evaporation rates, Atmos. Chem. Phys., 12, 225-235, doi:10.5194/acp-12-225-2012. 
Pandis, S. N., L. M. Russell, and J. H. Seinfeld (1994), The relationship between DMS flux and CCN concentration in remote marine regions, J. Geophys. Res., 99, 16,945-16,957.

Petäjä, T., R. L. Mauldin, III, E. Kosciuch, J. McGrath, T. Nieminen, P. Paasonen, M. Boy, A. Adamov, T. Kotiaho, and M. Kulmala (2009), Sulfuric acid and OH concentrations in a boreal forest site, Atmos. Chem. Phys., 9, 7435-7448.

Petäjä, T., M. Sipilä, P. Paasonen, T. Nieminen, T. Kurtén, I. K. Ortega, F. Stratmann, H. Vehkamäki, T. Berndt, and M. Kulmala (2011), Experimental Observation of Strongly Bound Dimers of Sulfuric Acid: Application to Nucleation in the Atmosphere, Physical Review Letters, 106(22), 228302, doi:10.1103/PhysRevLett.106.228302.

Peter, T., and J.-U. Grooß (2012), Stratospheric Ozone Depletion and Climate Change, chap. 4: Polar stratospheric clouds and sulfate aerosol particles: microphysics, denitrification and heterogeneous chemistry., pp. 108-144, The Royal Society of Chemistry.

Pitari, G., E. Mancini, V. Rizi, and D. T. Shindel (2002), Impact of future climate and emission changes on stratospheric aerosols and ozone, J. Atmos. Sci, 59, 414-440.

Plainaki, C., P. Paschalis, D. Grassi, H. Mavromichalaki, and M. Andriopoulou (2016), Solar energetic particle interactions with the venusian atmosphere, Annales Geophysicae, 34 (7), 595-608, doi:10.5194/angeo-34-595-2016.

Raes, F. (1995), Entrainment of free tropospheric aerosols as a regulating mechanism for cloud condensation nuclei in the remote marine boundary layer, J. Geophys. Res., 100, $2893-2903$.

Sawamura, P., J. P. Vernier, J. E. Barnes, T. A. Berkoff, E. J. Welton, L. AladosArboledas, F. Navas-Guzmán, G. Pappalardo, L. Mona, F. Madonna, D. Lange, M. Sicard, S. Godin-Beekmann, G. Payen, Z. Wang, S. Hu, S. N. Tripathi, C. Cordoba- 
Jabonero, and R. M. Hoff (2012), Stratospheric AOD after the 2011 eruption of Nabro volcano measured by lidars over the Northern Hemisphere, Environ. Res. Lett., 7(3), 034,013, doi:10.1088/1748-9326/7/3/034013.

Seinfeld, J. H., and S. N. Pandis (1998), Atmospheric Chemistry and Physics: From Air Pollution to Climate Change, John Wiley \& Sons, New York.

Sihto, S.-L., M. Kulmala, V.-M. Kerminen, M. Dal Maso, T. Petäjä, I. Riipinen, H. Korhonen, F. Arnold, R. Janson, M. Boy, A. Laaksonen, and K. E. J. Lehtinen (2006), Atmospheric sulphuric acid and aerosol formation: implications from atmospheric measurements for nucleation and early growth mechanisms, Atmos. Chem. Phys., 6, 40794091.

Sipilä, M., T. Berndt, T. Petäjä, D. Brus, J. Vanhanen, F. Stratmann, J. Patokoski, R. L. Mauldin, A.-P. Hyvärinen, H. Lihavainen, and M. Kulmala (2010), The Role of Sulfuric Acid in Atmospheric Nucleation, Science, 327, 1243-1246, doi:10.1126/science.1180315.

Solomon, S., J. S. Daniel, R. R. Neely, J.-P. Vernier, E. G. Dutton, and L. W. Thomason (2011), The Persistently Variable Background Stratospheric Aerosol Layer and Global Climate Change, Science, 333, 866-870, doi:10.1126/science.1206027.

Spracklen, D. V., K. S. Carslaw, M. Kulmala, V.-M. Kerminen, S.-L. Sihto, I. Riipinen, J. Merikanto, G. W. Mann, M. P. Chipperfield, A. Wiedensohler, W. Birmili, and H. Lihavainen (2008), Contribution of particle formation to global cloud condensation nuclei concentrations, Geophys. Res. Lett., 35, L06808, doi:10.1029/2007GL033038.

Stier, P., J. Feichter, S. Kinne, S. Kloster, E. Vignati, J. Wilson, L. Ganzeveld, I. Tegen, M. Werner, Y. Balkanski, M. Schulz, O. Boucher, A. Minikin, and A. Petzold (2005), The aerosol-climate model ECHAM5-HAM, Atmos. Chem. Phys., 5, 1125-1156. 
Trinkaus, H. (1983), Theory of the nucleation of multicomponent precipitates, Phys. Rev. B., 27, 7372-7378.

Vehkamäki, H. (2006), Classical Nucleation Theory in Multicomponent Systems, Springer, Berlin Heidelberg.

Vehkamäki, H., M. Kulmala, I. Napari, K. E. J. Lehtinen, C. Timmreck, M. Noppel, and A. Laaksonen (2002), An improved parameterization for sulfuric acid/water nucleation rates for tropospheric and stratospheric conditions, J. Geophys. Res., 10\%, 10.1029/2002JD00.

Vehkamäki, H., M. Kulmala, and K. E. J. Lehtinen (2003), Modelling binary homogeneous nucleation of water-sulfuric acid vapours: parameterisation for high temperature emissions, Environ. Sci. Technol., 37, 3392-3398.

Vernier, J.-P., L. W. Thomason, J.-P. Pommereau, A. Bourassa, J. Pelon, A. Garnier, A. Hauchecorne, L. Blanot, C. Trepte, D. Degenstein, and F. Vargas (2011), Major influence of tropical volcanic eruptions on the stratospheric aerosol layer during the last decade, Geophys. Res. Lett., 38, L12807, doi:10.1029/2011GL047563.

Vignati, E., J. Wilson, and P. Stier (2004), M7: An efficient size-resolved aerosol microphysics module for large-scale aerosol transport models, Journal of Geophysical Research: Atmospheres, $109(\mathrm{D} 22)$, n/a-n/a, doi:10.1029/2003JD004485, d22202.

Weber, R. J., J. Marti, P. H. McMurry, F. Eisele, D. J. Tanner, and A. Jefferson (1996), Measured atmospheric new particle formation rates: implications for nucleation mechanisms, Chem. Eng. Comm, 151, 53-64.

Wexler, A. S., F. W. Lurmann, and J. H. Seinfeld (1994), Modelling urban and regional aerosols: I. Modeling development, Atm. Environ., 28, 531-546. 
Wilemski, G., and B. E. Wyslouzil (1995), Binary nucleation kinetics. I. Self-consistent size distribution, J. Chem. Phys., 103, 1127-1136.

Yamamoto, M., and M. Takahashi (2006), An aerosol transport model based on a twomoment microphysical parameterization in the Venus middle atmosphere: Model description and preliminary experiments, Journal of Geophysical Research (Planets), 111, E08002, doi:10.1029/2006JE002688.

Young, A. T. (1983), Venus cloud microphysics, Icarus, 56, 568-577, doi:10.1016/00191035(83)90174-4.

$\mathrm{Yu}, \mathrm{F}$. (2008), Updated $\mathrm{H}_{2} \mathrm{SO}_{4}-\mathrm{H}_{2} \mathrm{O}$ binary homogeneous nucleation look-up tables, Journal of Geophysical Research (Atmospheres), 113, D24201, doi:10.1029/2008JD010527.

Yu, F. (2010), Ion-mediated nucleation in the atmosphere: Key controlling parameters, implications, and look-up table, J. Geophys. Res., 115, D03206, doi: 10.1029/2009JD012630.

Yu, F., G. Luo, T. S. Bates, B. Anderson, A. Clarke, V. Kapustin, R. M. Yantosca, Y. Wang, and S. Wu (2010), Spatial distributions of particle number concentrations in the global troposphere: Simulations, observations, and implications for nucleation mechanisms, Journal of Geophysical Research: Atmospheres, 115(D17), n/a-n/a, doi: 10.1029/2009JD013473, d17205.

Zhang, K., D. O’Donnell, J. Kazil, P. Stier, S. Kinne, U. Lohmann, S. Ferrachat, B. Croft, J. Quaas, H. Wan, S. Rast, and J. Feichter (2012), The global aerosol-climate model ECHAM-HAM, version 2: Sensitivity to improvements in process representations, Atmos. Chem. Phys., 12, 8911-8949, doi:10.5194/acp-12-8911-2012. 
Zhang, Y., P. H. McMurry, F. Yu, and M. Z. Jacobson (2010), A comparative study of nucleation parameterizations: 1. Examination and evaluation of the formulations, Journal of Geophysical Research (Atmospheres), 115, D20212, doi:10.1029/2010JD014150.

Zhao, J., F. L. Eisele, M. Titcombe, C. Kuang, and P. H. McMurry (2010), Chemical ionization mass spectrometric measurements of atmospheric neutral clusters using the cluster-cims, J. Geophys. Res., 115, D08,205, doi:10.1029/2009JD012606.

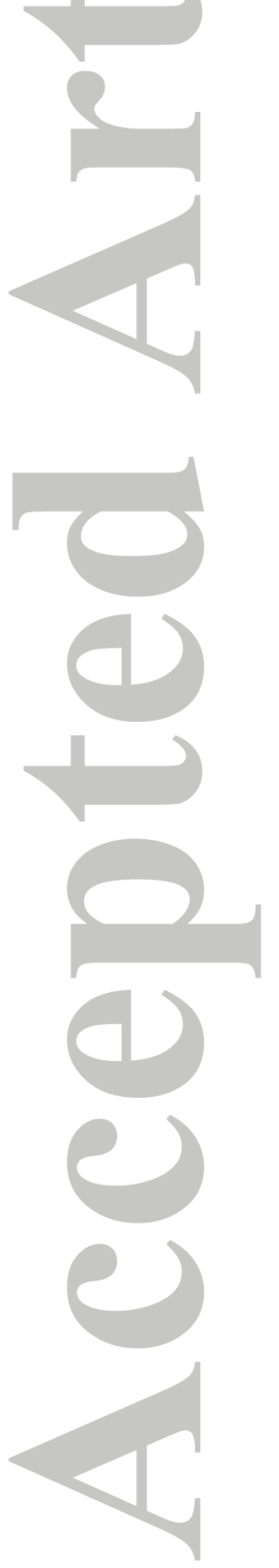



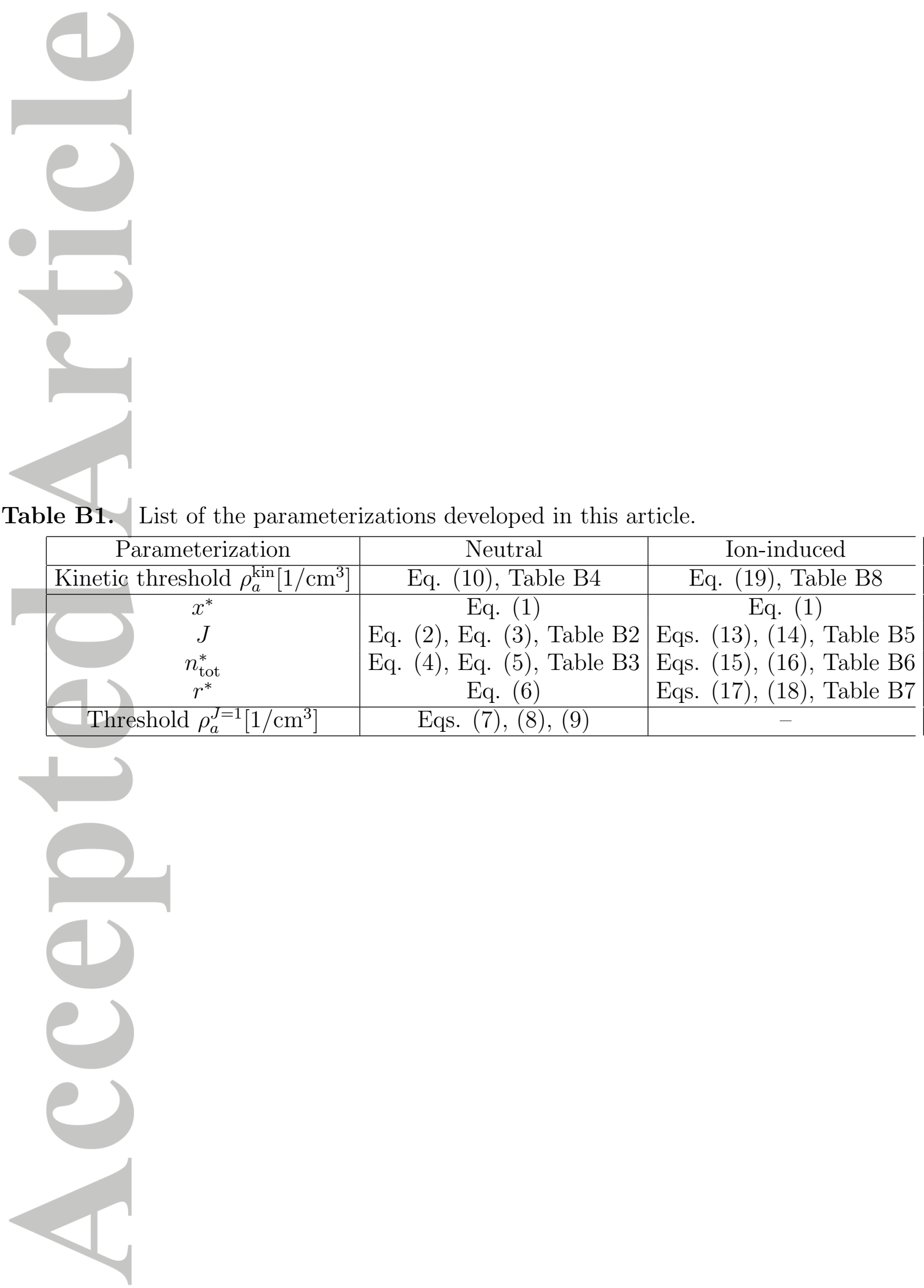

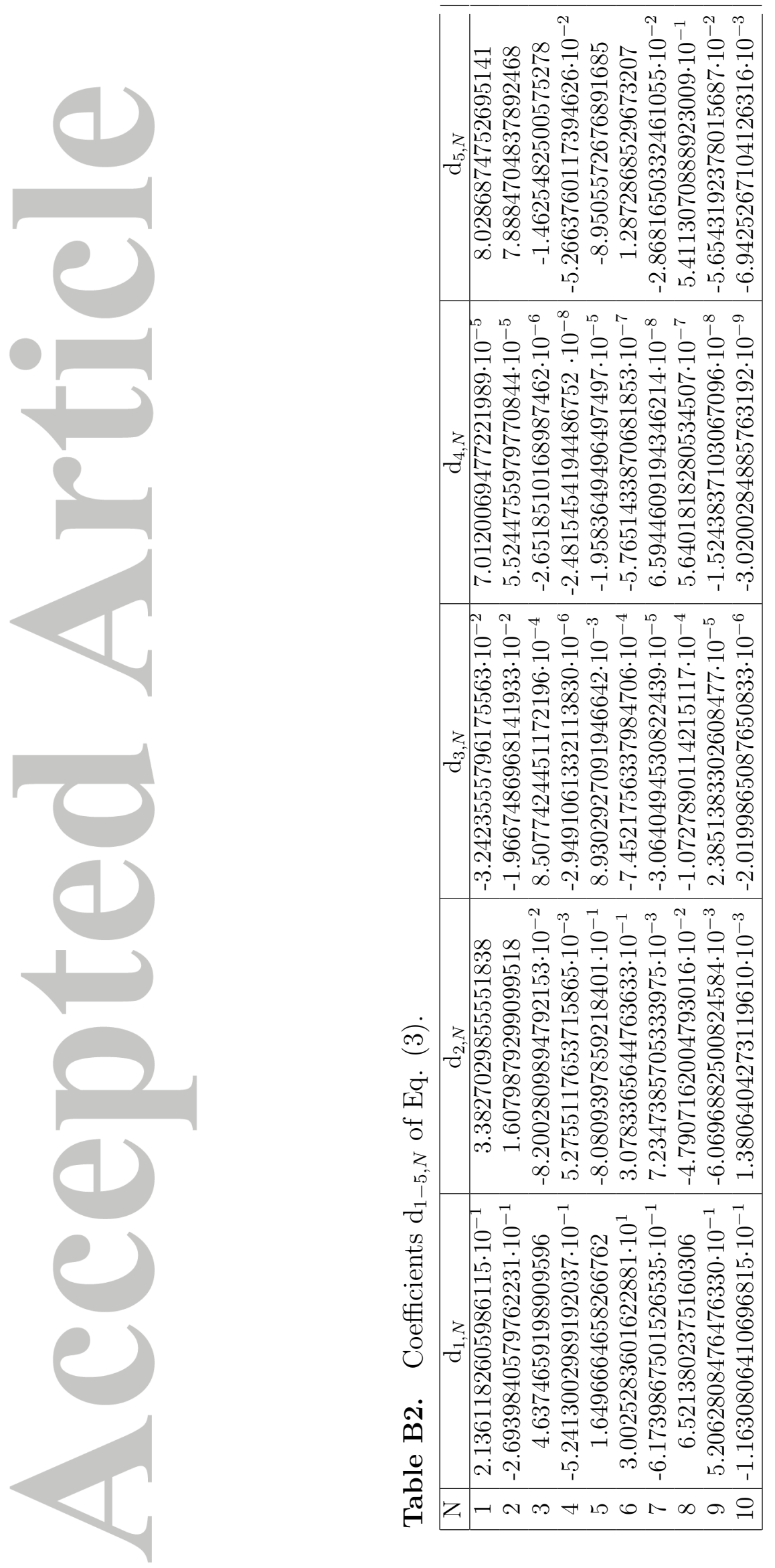

(C)2017 American Geophysical Union. All Rights Reserved. 

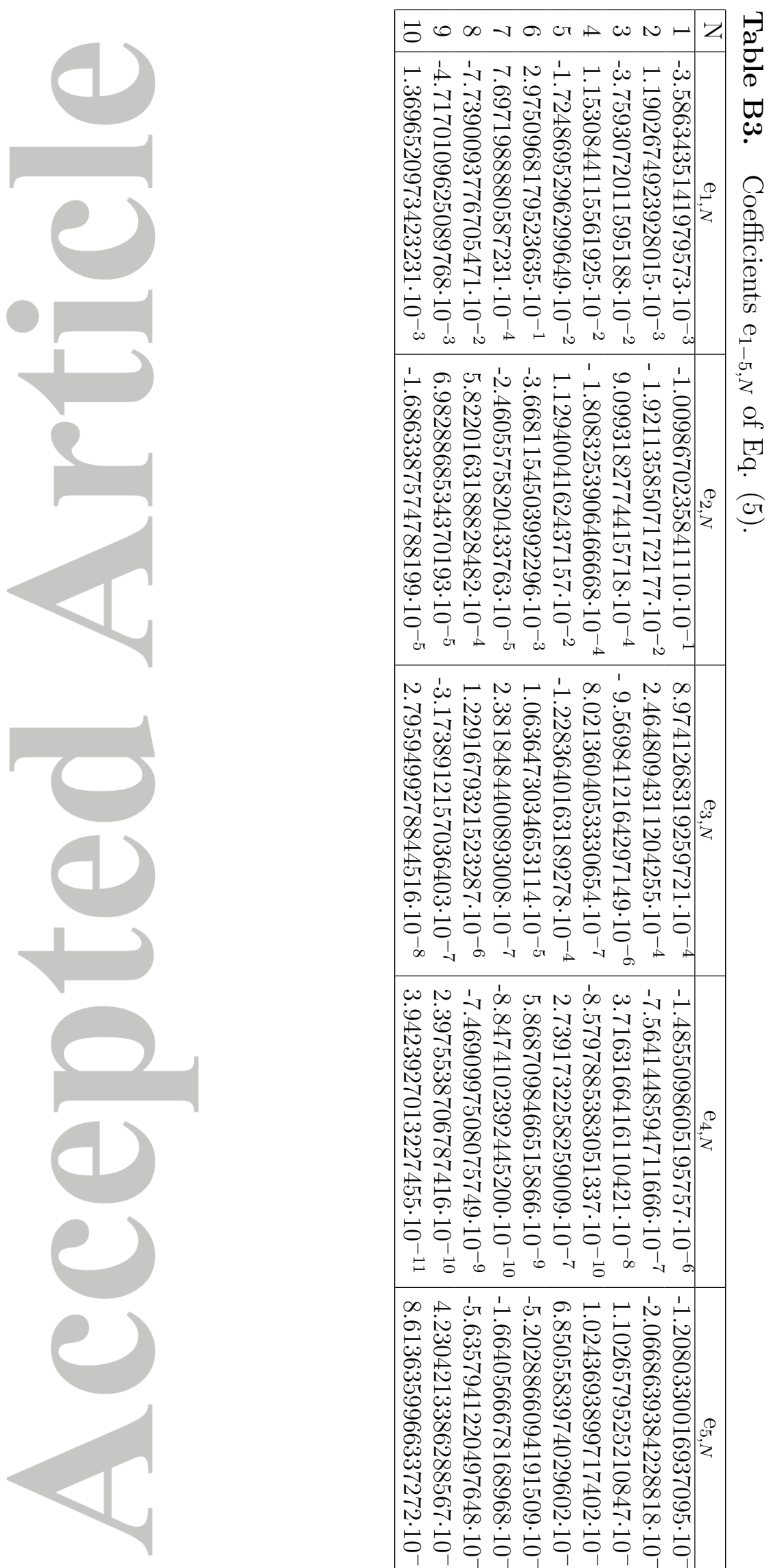

(C) $2017^{\star}$ American Geophysical Union. All Rights Reserved. 

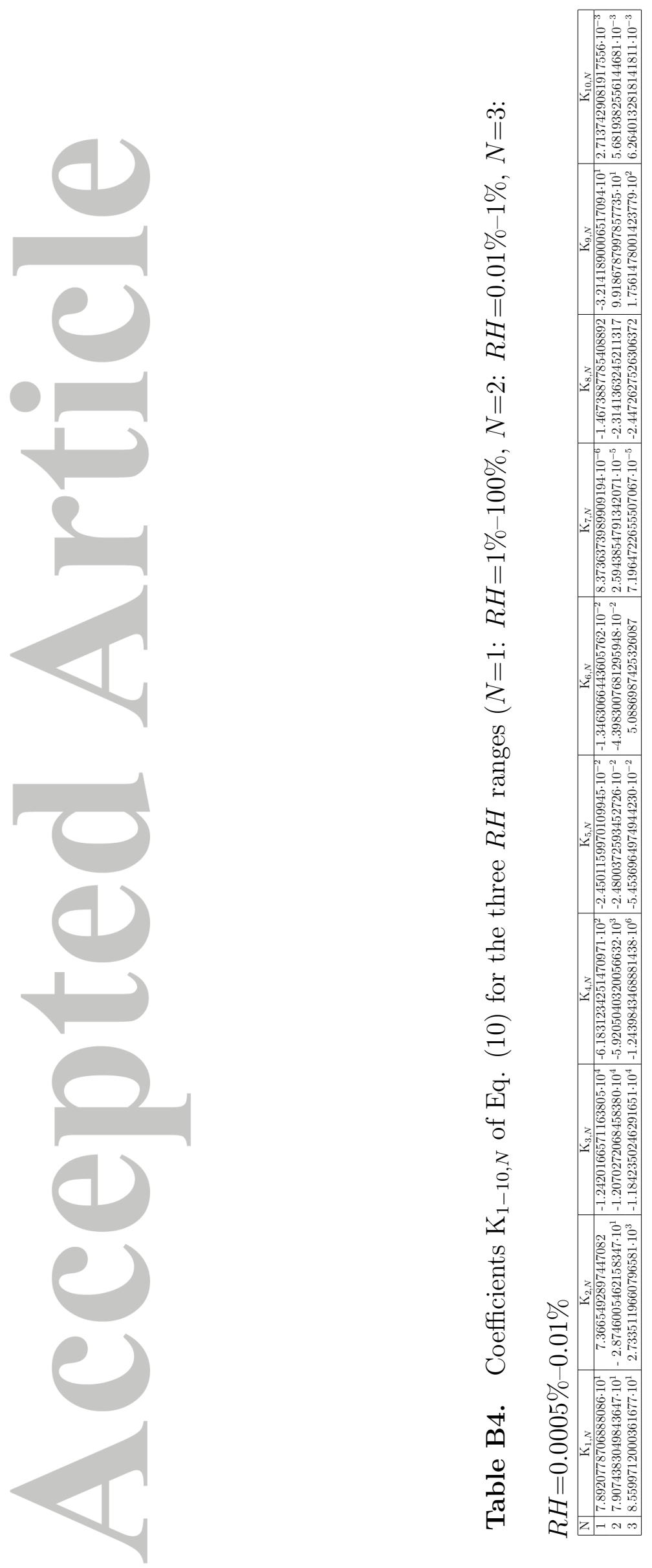

(C)2017 American Geophysical Union. All Rights Reserved. 


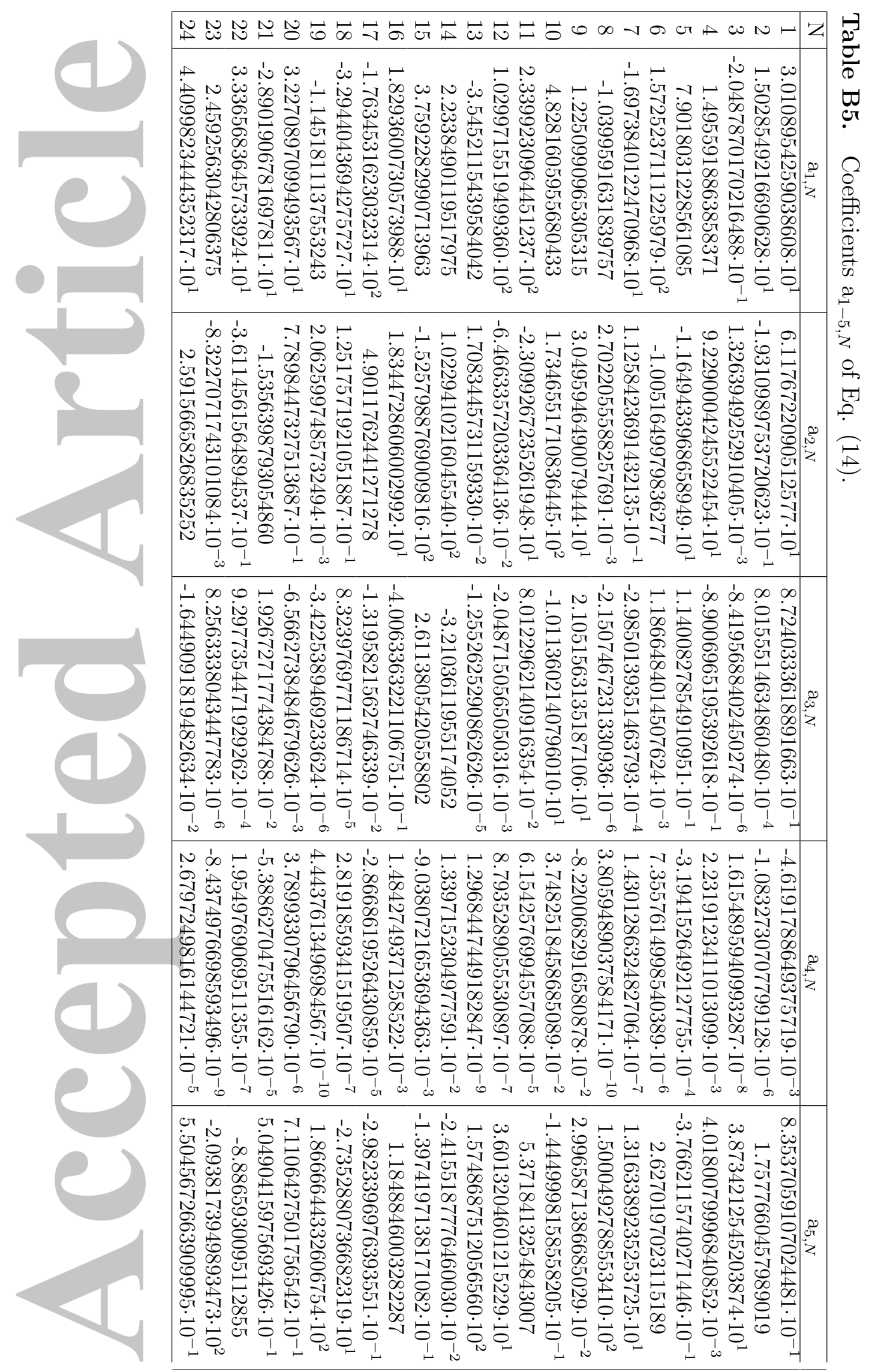

(C)2017 American Geophysical Union. All Rights Reserved. 


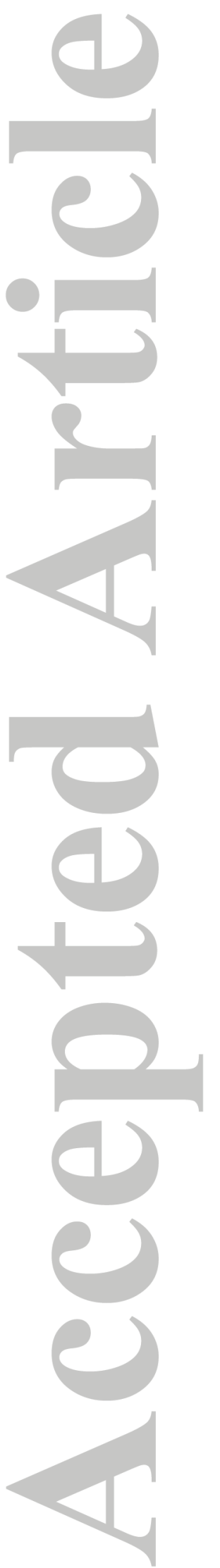

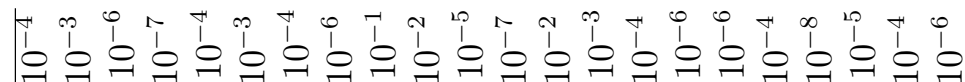

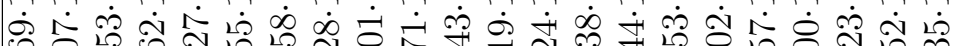
눙 긍 ż -

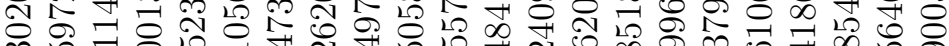

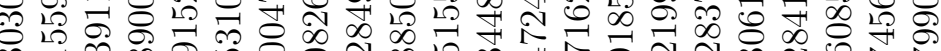

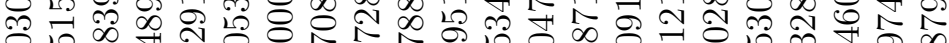

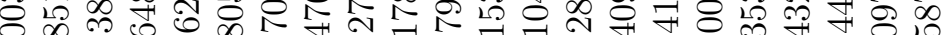

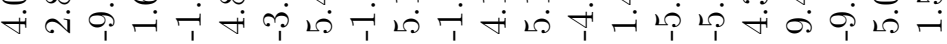

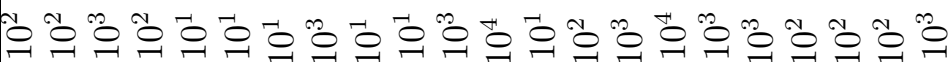
வ்

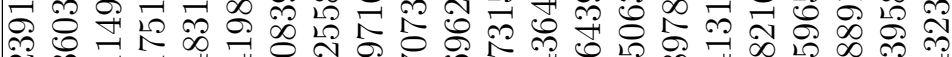
î

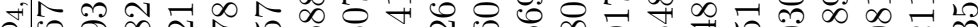

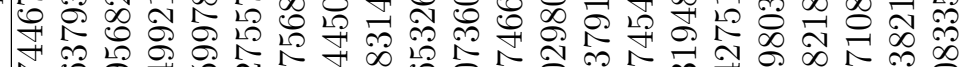

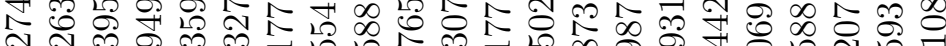

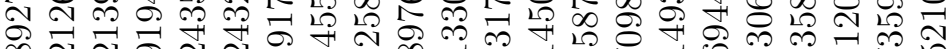

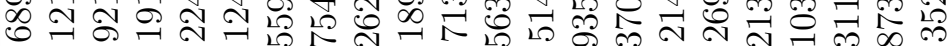

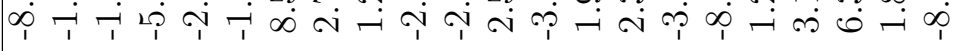

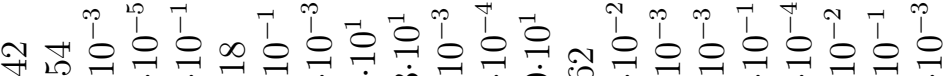
ठ ஜिं F 군 急

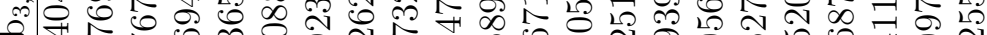

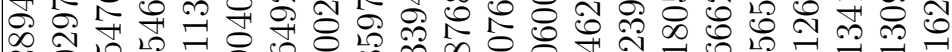

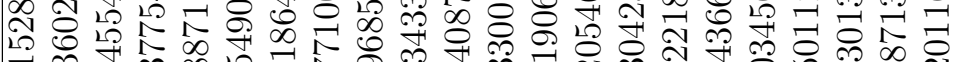
年 궁요 0

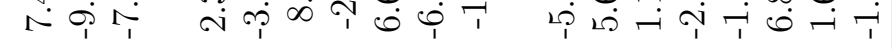

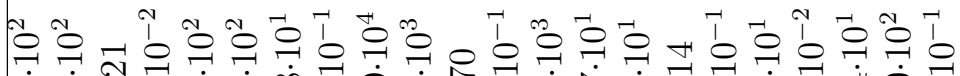

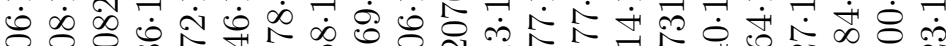

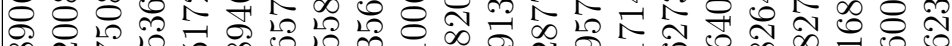

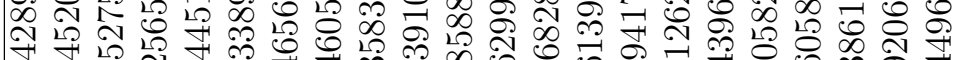
z

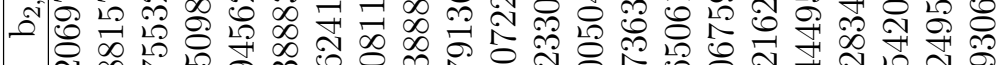

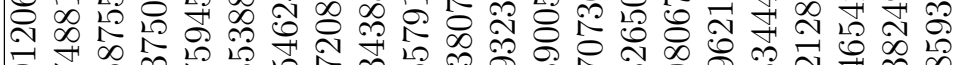

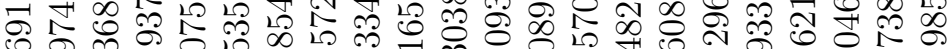

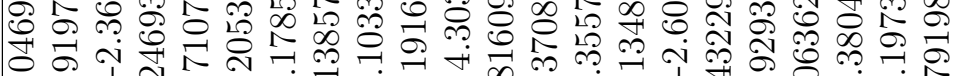
வீ

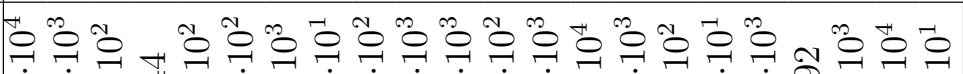

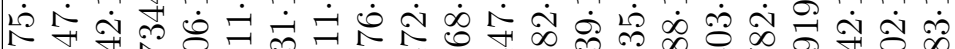

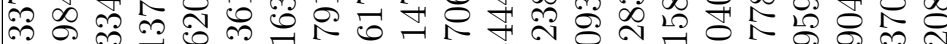

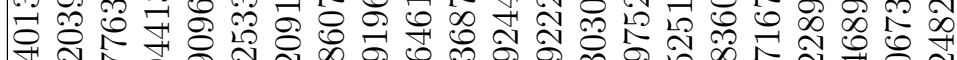
z

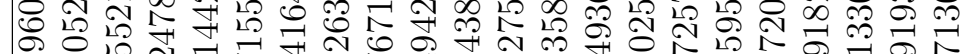

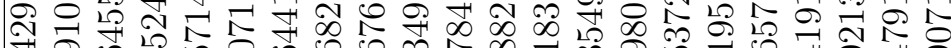
为

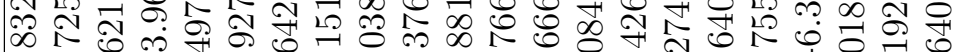

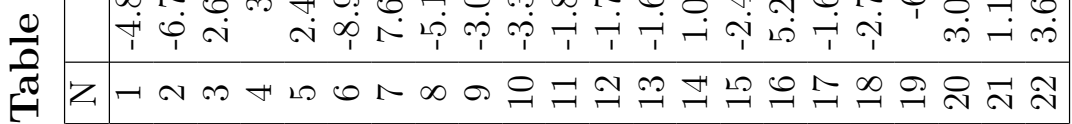

(C)2017 American Geophysical Union. All Rights Reserved. 


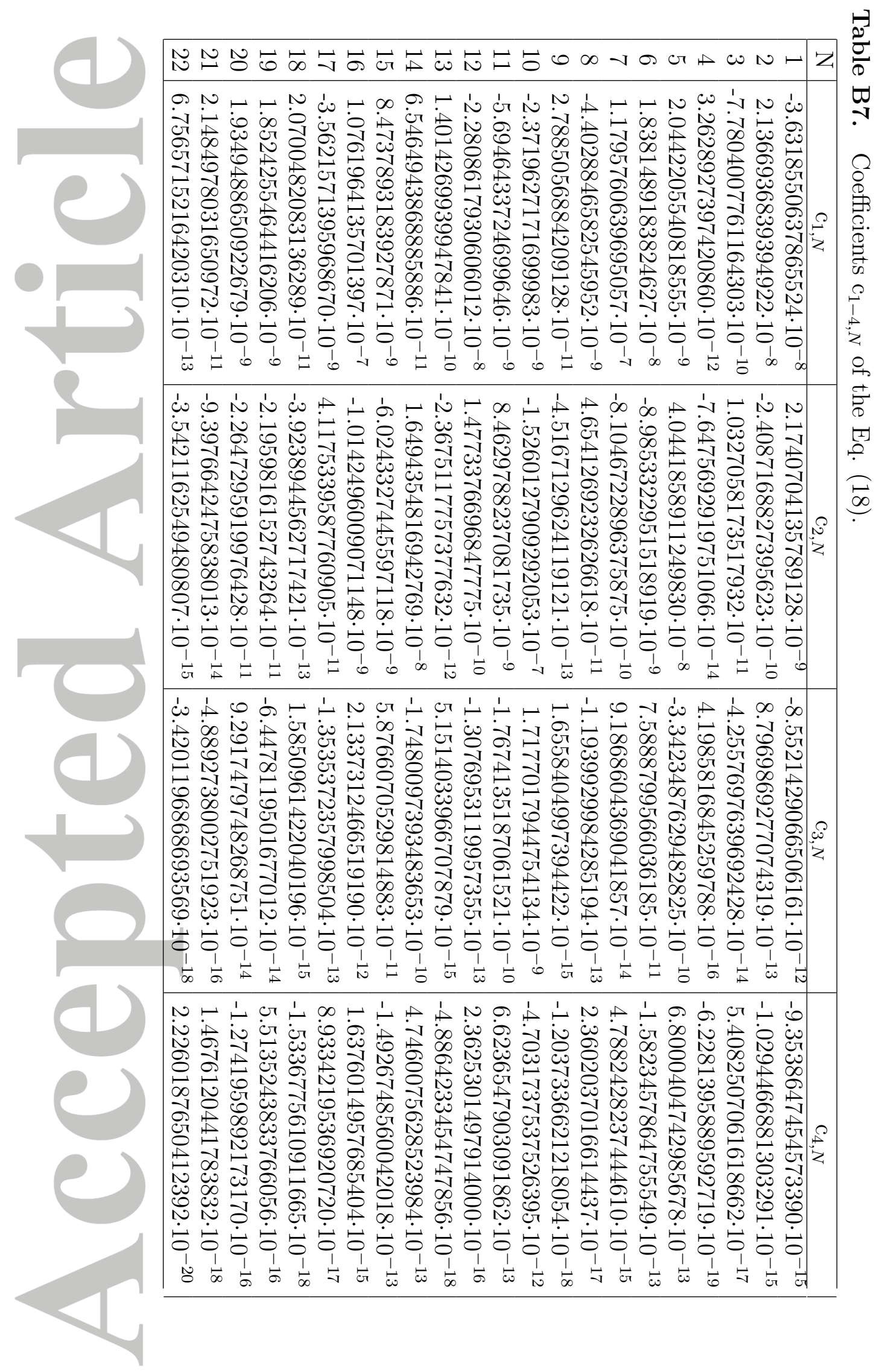

(C)2017 American Geophysical Union. All Rights Reserved. 
Table B8. Coefficients $\mathrm{L}_{1-24}$ of Eq. (19).

\begin{tabular}{|c|c|c|c|}
\hline$N$ & $\mathrm{~L}_{N}$ & $\mathrm{~N}$ & $\mathrm{~L}_{N}$ \\
\hline 1 & $5.3742280876674478 \cdot 10^{1}$ & 13 & $3.0372070669934950 \cdot 10^{-6}$ \\
\hline 2 & $-6.6837931590012266 \cdot 10^{-3}$ & 14 & $3.8255873977423475 \cdot 10^{-6}$ \\
\hline 3 & $-1.0142598385422842 \cdot 10^{-1}$ & 15 & $-1.2344793083561629 \cdot 10^{-4}$ \\
\hline 4 & -6.4170597272606873 & 16 & $-1.7959048869810192 \cdot 10^{-5}$ \\
\hline 5 & $-6.4315798914824518 \cdot 10^{-1}$ & 17 & $-3.2165622558722767 \cdot 10^{-7}$ \\
\hline 6 & $-2.4428391714772721 \cdot 10^{-2}$ & 18 & $-4.7136923780988659 \cdot 10^{-9}$ \\
\hline 7 & $-3.5356658734539019 \cdot 10^{-4}$ & 19 & $1.1873317184482216 \cdot 10^{-7}$ \\
\hline 8 & $2.5400015099140506 \cdot 10^{-5}$ & 20 & $1.5685860354866621 \cdot 10^{-8}$ \\
\hline 9 & $-2.7928900816637790 \cdot 10^{-4}$ & 21 & $-1.4329645891059557 \cdot 10^{4}$ \\
\hline 10 & $4.4108573484923690 \cdot 10^{-2}$ & 22 & $1.3842599842575321 \cdot 10^{-1}$ \\
\hline 11 & $6.3943789012475532 \cdot 10^{-3}$ & 23 & $-4.1376265912842938 \cdot 10^{-4}$ \\
\hline 12 & $2.3164296174966580 \cdot 10^{-4}$ & 24 & $3.9147639775826004 \cdot 10^{-7}$ \\
\hline
\end{tabular}



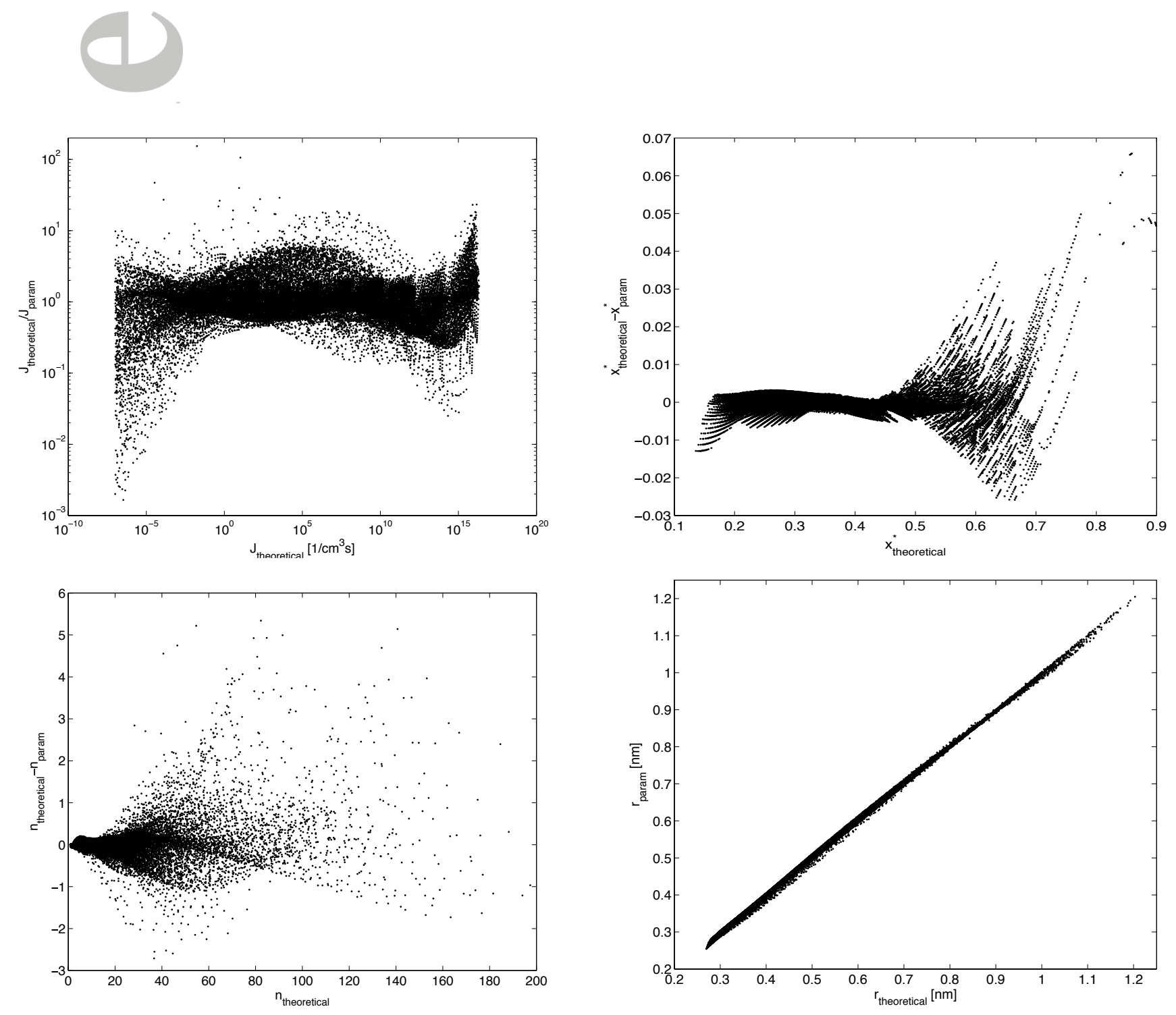

Figure 1. Neutral particle formation: Comparison between the parameterized and the theoretical values for the particle formation rate $J$ (top left), the critical cluster mole fraction $x^{*}$ (top right), the total number of molecules in the critical cluster $n_{\text {tot }}^{*}$ (bottom left) and the critical cluster radius $r^{*}$ (bottom right).

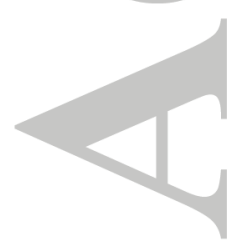

(C)2017 American Geophysical Union. All Rights Reserved. 

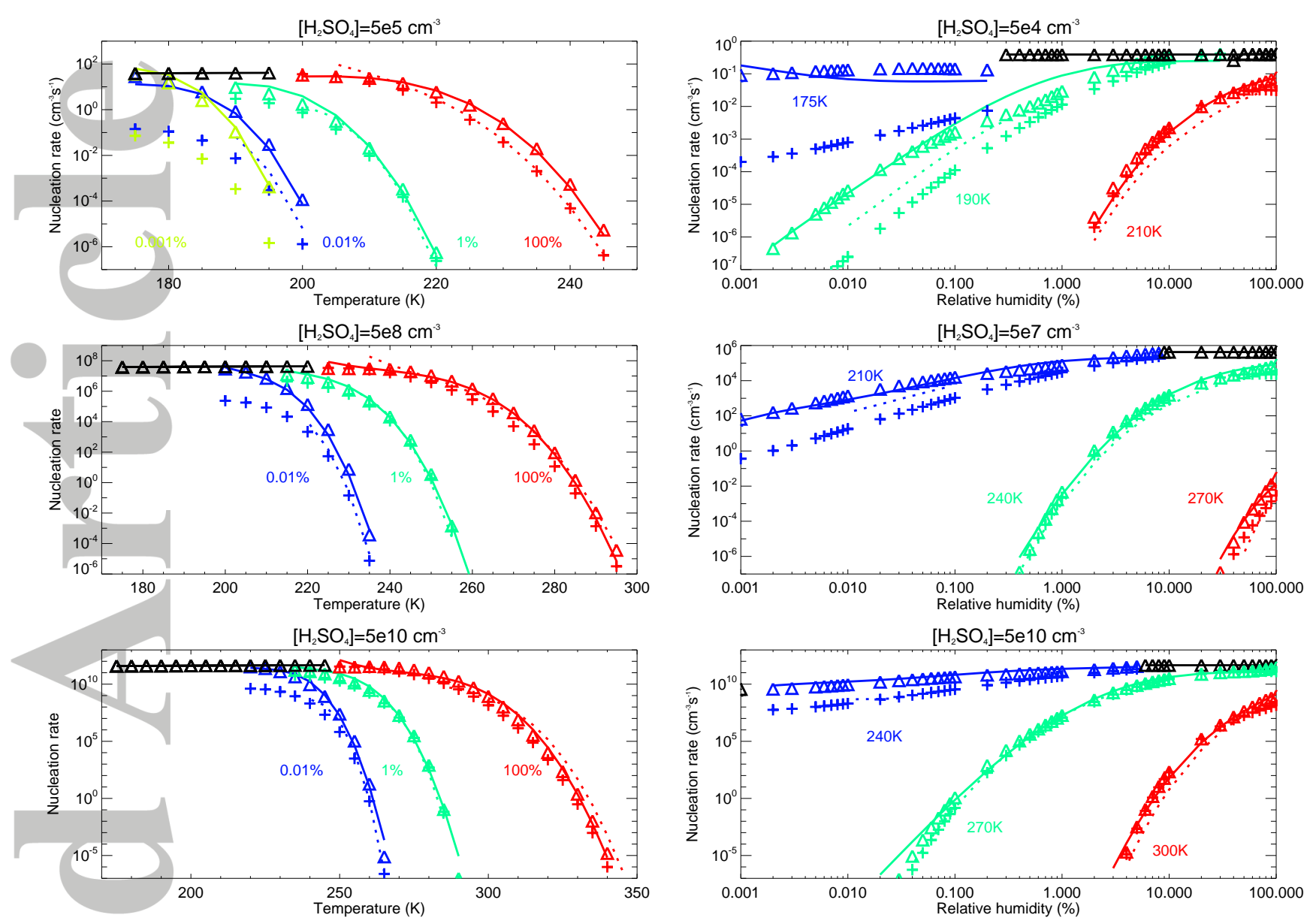

Figure 2. Left: The neutral particle formation rate $J$ as a function of temperature at different total sulfuric acid concentrations and relative humidities. The relative humidities correspond to different colors as marked in the plot. Right: The particle formation rate as a function of relative humidity at different total sulfuric acid concentrations and temperatures. The temperatures correspond to different colors as marked in the plots. The sulfuric acid concentrations $\left[\mathrm{H}_{2} \mathrm{SO}_{4}\right]$ are given in the plot titles $\left(\mathrm{cm}^{-3}\right)$. The crosses and dashed lines show, respectively, the old theoretical values and the old parameterization [Vehkamäki et al., 2002]. The triangles and solid lines show, respectively, the new theoretical values and the new parameterized rates. The black triangles and solid lines show the kinetic particle formation rates calculated using Eqs. (11) and (12). 
a)

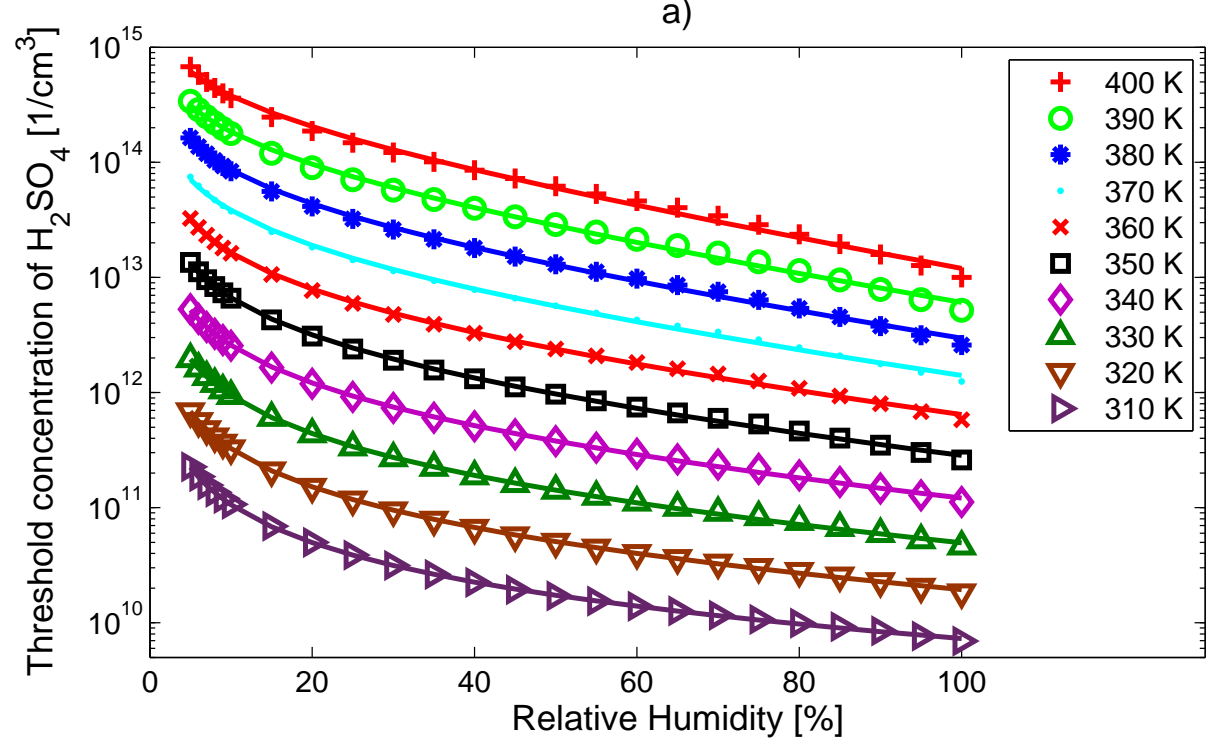

b)

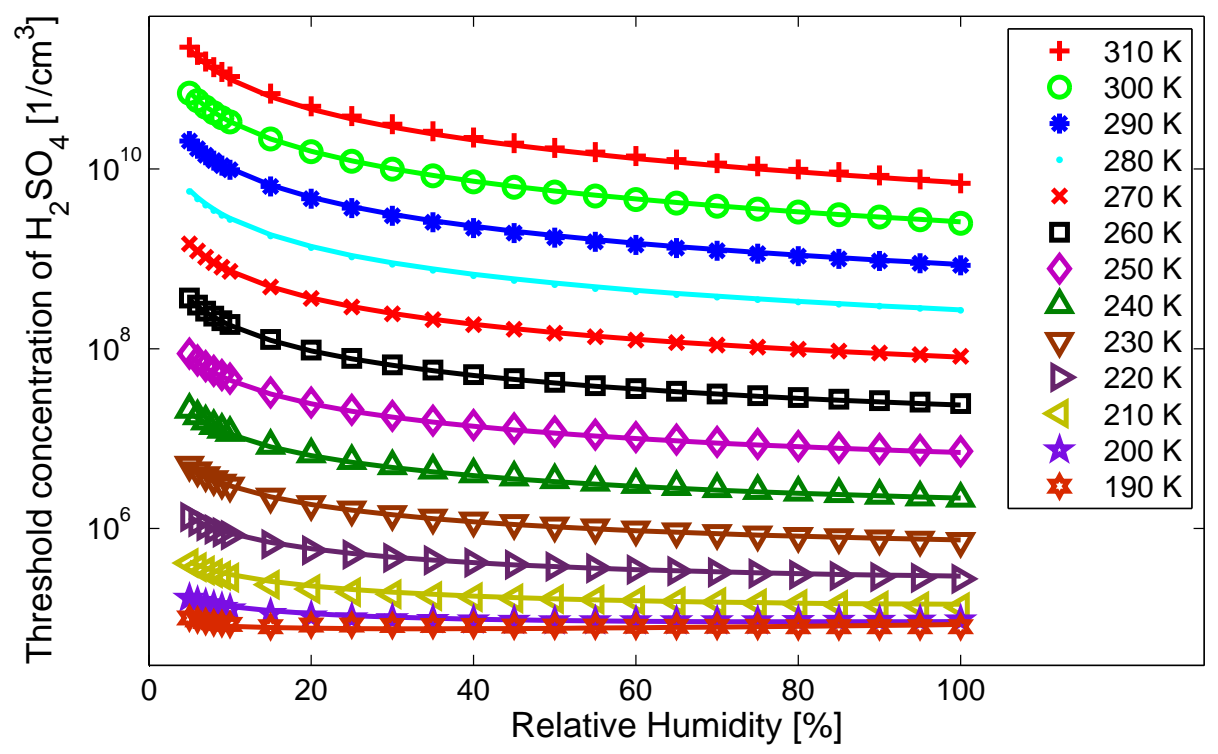

Figure 3. The threshold sulfuric acid concentration parameterization (lines, data with symbols) yielding neutral particle formation rates $1 \mathrm{~cm}^{-3} \mathrm{~s}^{-1}$ as function of relative humidity. Upper panel: temperature range from $310 \mathrm{~K}$ to $400 \mathrm{~K}$. Lower panel: 190-310 K. The temperatures are as given in the legend.

(C)2017 American Geophysical Union. All Rights Reserved. 

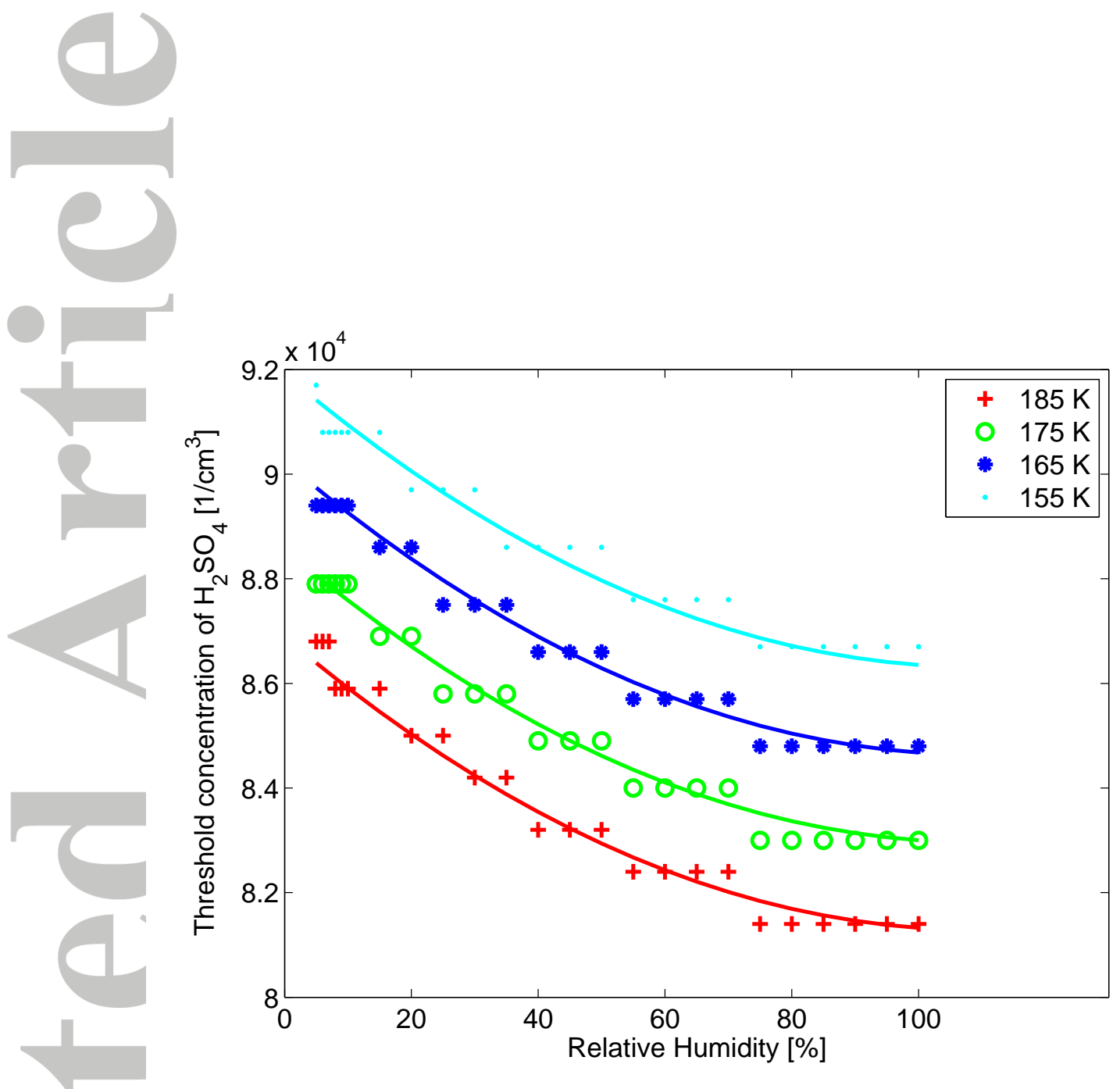

Figure 4. The threshold sulfuric acid concentration parameterization (lines, data with symbols) yielding neutral particle formation rates $1 \mathrm{~cm}^{-3} \mathrm{~s}^{-1}$ in the kinetic range, at temperatures ranging from $155 \mathrm{~K}$ to $185 \mathrm{~K}$. The step-wise behavior of the data points is an artifact of the sulfuric acid grid resolution we used for calculating the data. 

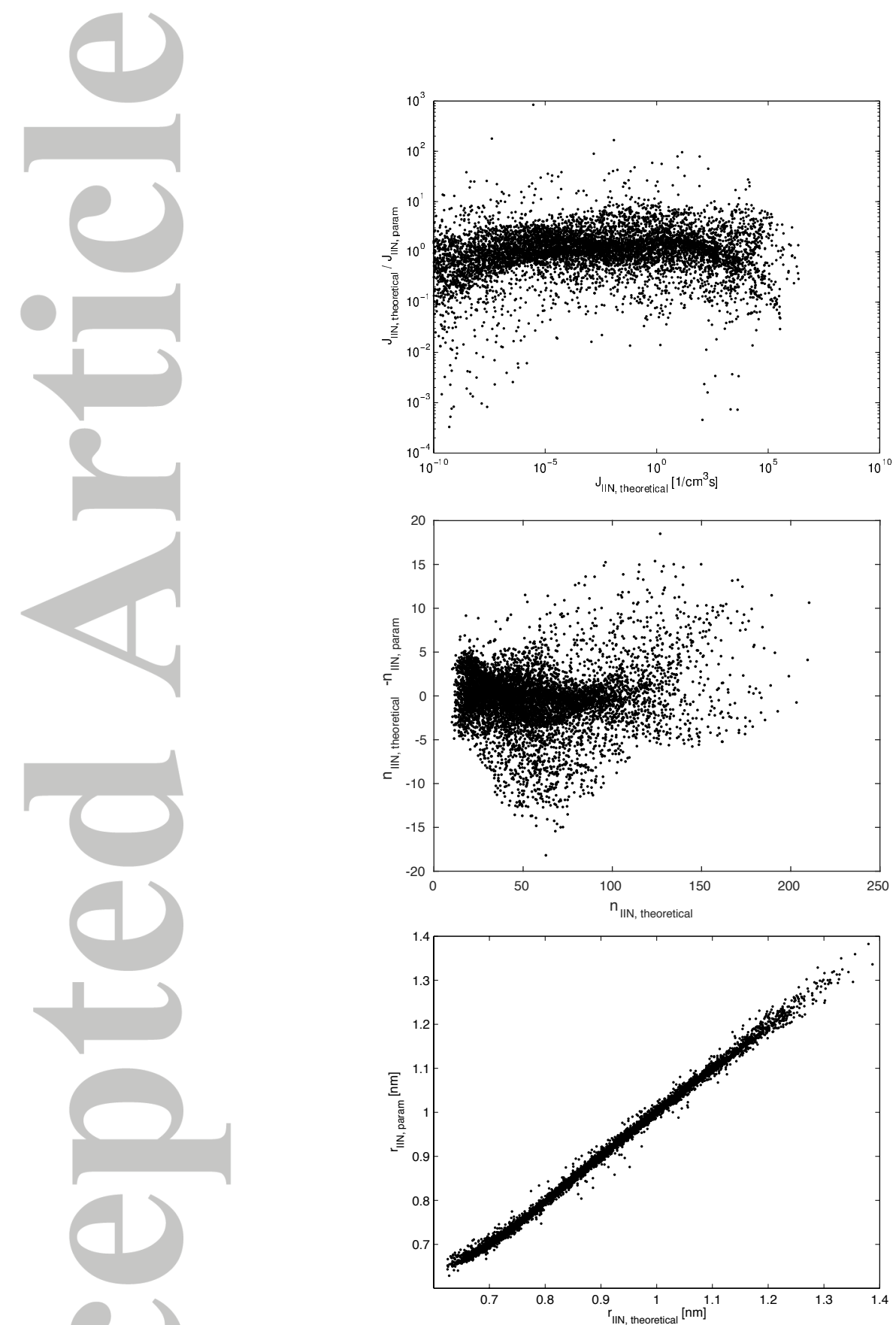

Figure 5. Ion-induced case: Comparison between the parameterized and the theoretical values of the particle formation rate $J$ (top), for the total number of molecules in the critical cluster $n_{\text {tot }}^{*}$ (middle), and for the critical cluster radius $r^{*}$ (bottom).

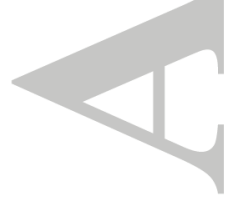



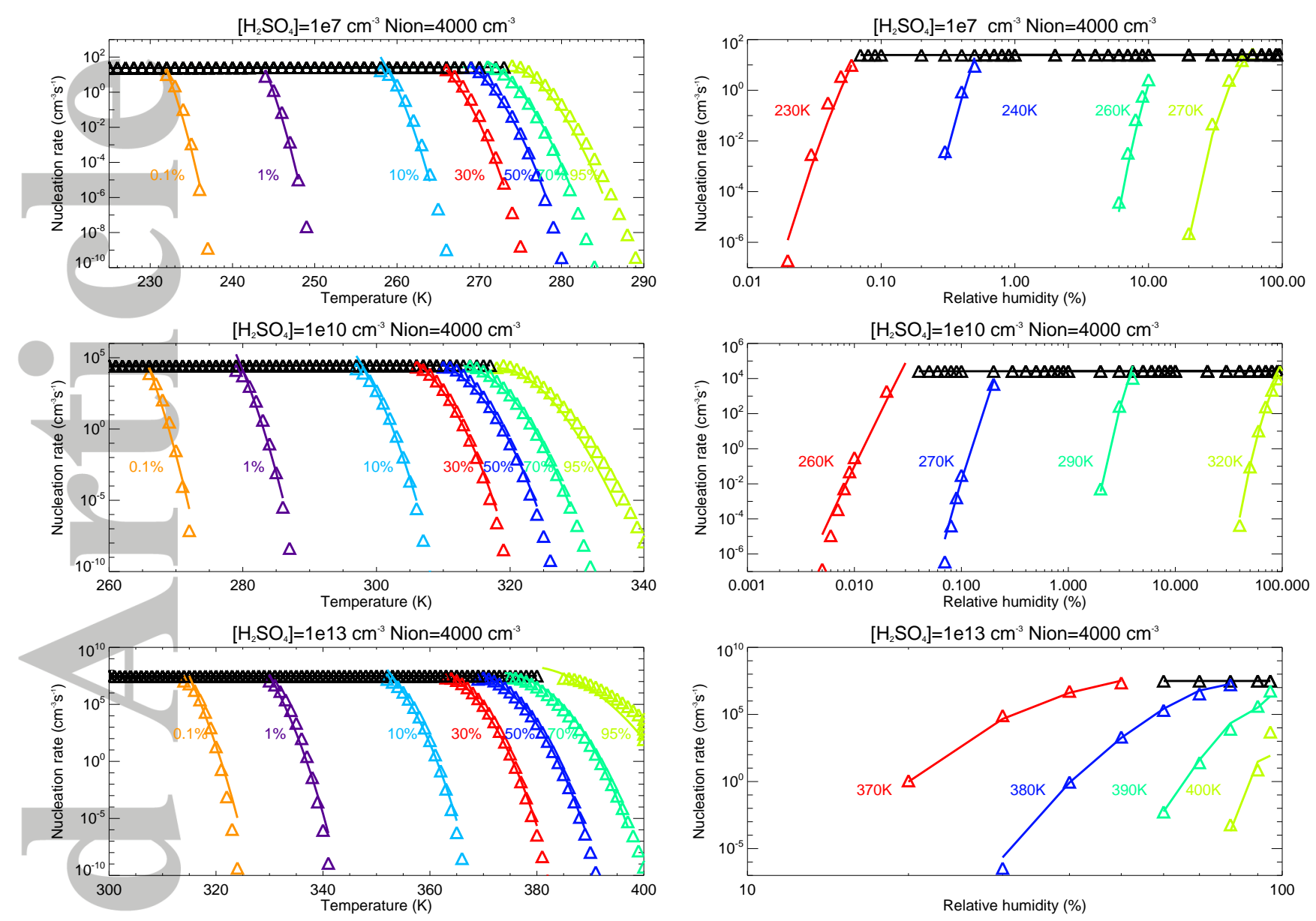

Figure 6. Left: The ion-induced particle formation rate $J_{\text {ion }}$ as a function of temperature at different total sulfuric acid concentrations and relative humidities. The relative humidities correspond to the colors as marked in the plot. Right: The particle formation rate as a function of relative humidity at different total sulfuric acid concentrations and temperatures. The temperatures correspond to the colors as marked in the plot. The sulfuric acid concentrations $\left[\mathrm{H}_{2} \mathrm{SO}_{4}\right]$ are given in the plot titles $\left(\mathrm{cm}^{-3}\right)$. The triangles and solid lines show, respectively, the theoretical values and the parameterization in the nucleation range. The black triangles and lines show, respectively, the kinetic range values calculated with Eq. (20).

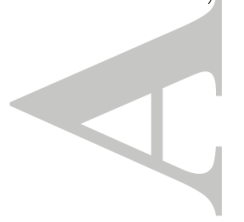




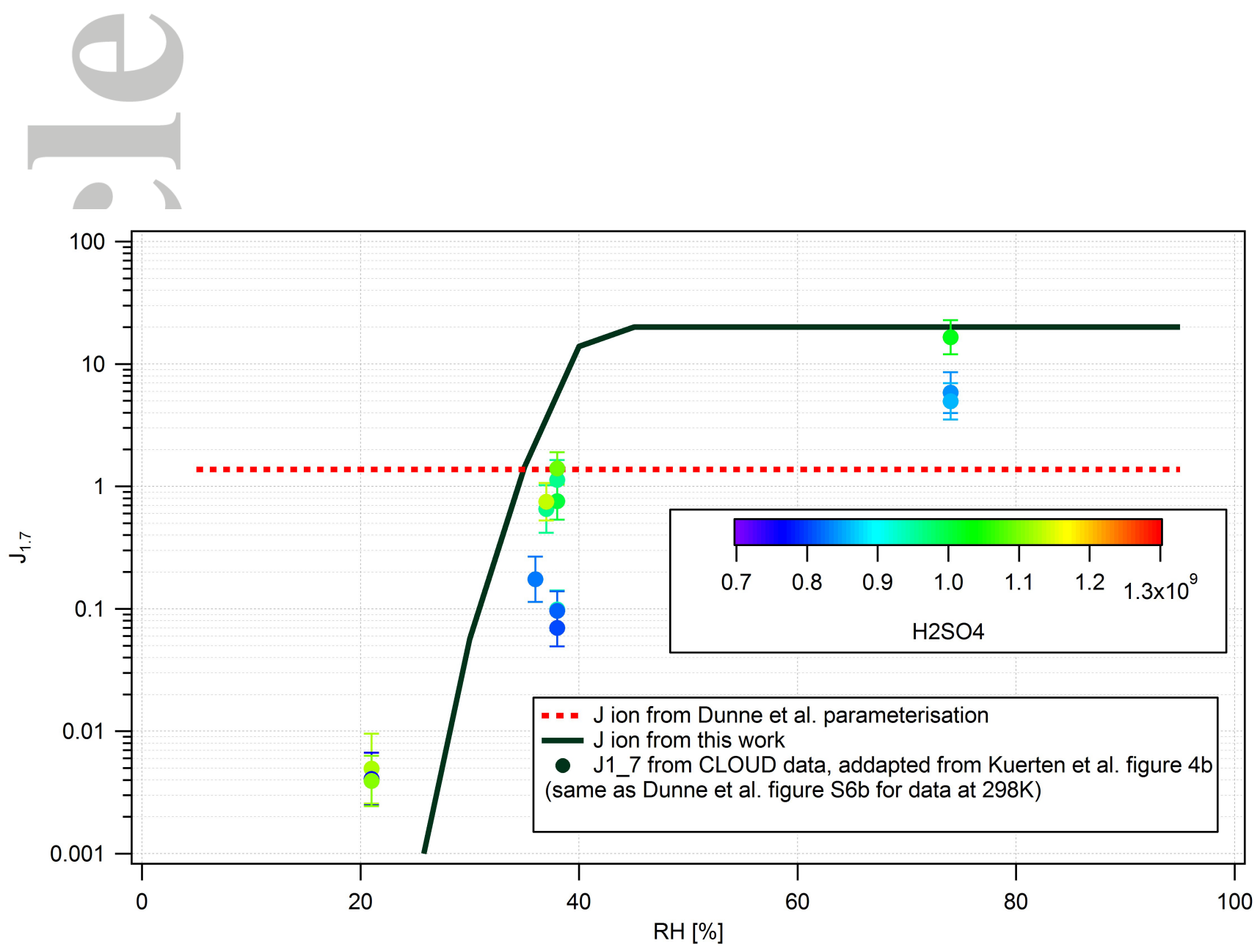

Figure 7. Comparison of particle formation rates as a function of relative humidity given by the parameterization presented in this paper (black solid line, calculated for $\left[\mathrm{H}_{2} \mathrm{SO}_{4}\right]=10^{9}$ $\mathrm{cm}^{-3}$ ), the parameterization of Dunne et al. [2016] (red dotted line) and CLOUD measurements (filled circles with color scale giving the sulfuric acid concentration) for an ion-induced particle formation case at $298 \mathrm{~K}$ [see also Figure S6b of Dunne et al., 2016].

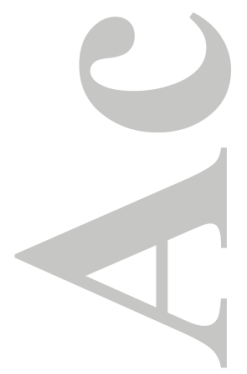



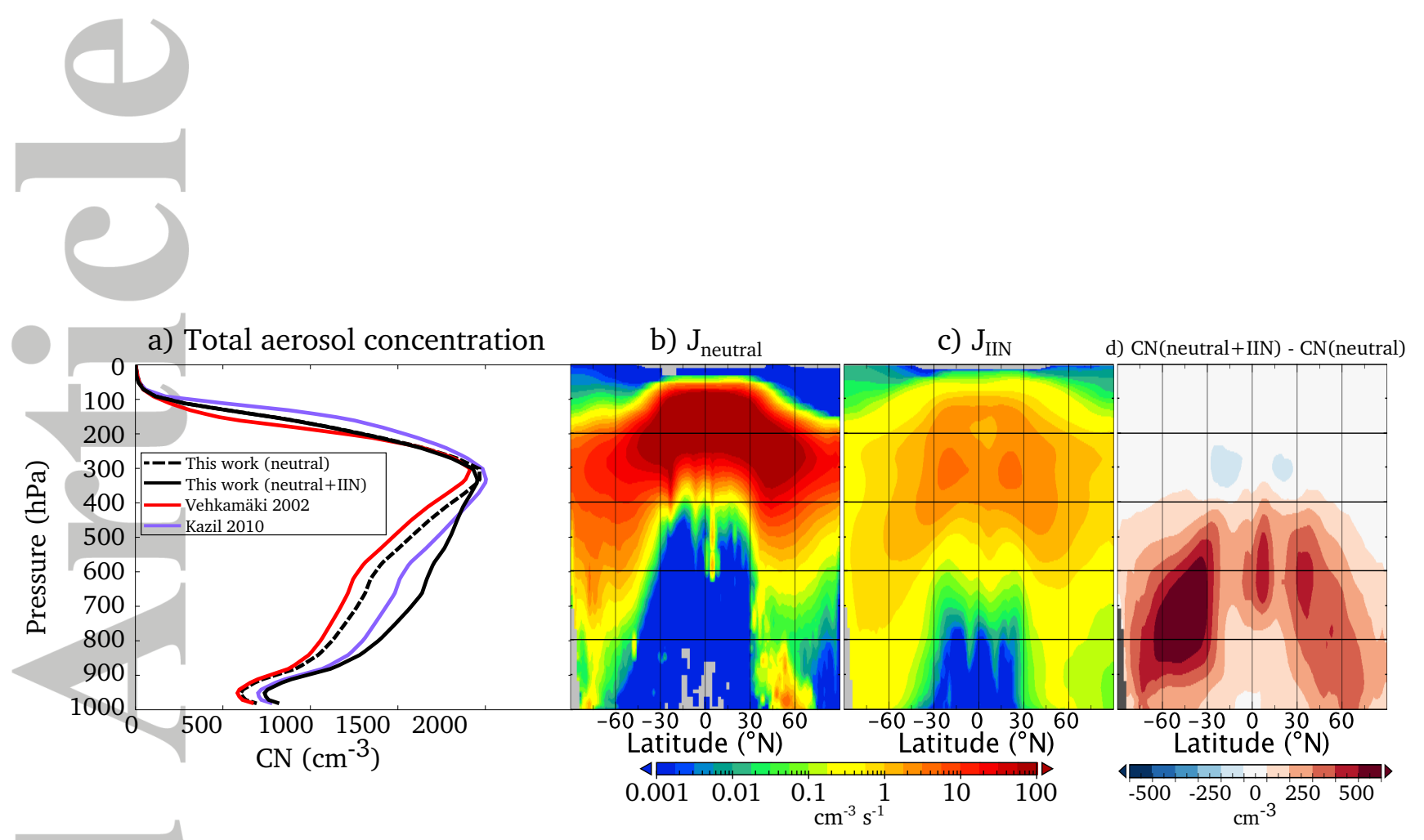

Figure 8. a) Comparison of the total aerosol concentration $\left(\mathrm{CN}, d_{p}>3 \mathrm{~nm}\right)$ in four simulations with the global aerosol model ECHAM5.5-HAM2: new neutral parameterization (black dashed line), new parameterization with neutral and ion-induced pathways (black solid line), Vehkamäki et al. [2002] parameterization (red solid line) and Kazil et al. [2010] (magenta), (b) neutral and (c) ion-induced nucleation rate from the simulation with both nucleation pathways active, and (d) difference zonal plot of the total aerosol concentration in the simulation with both neutral and ion pathway minus the simulation with the neutral pathway only. 
$\left[\mathrm{H}_{2} \mathrm{SO}_{4}\right]=1 \mathrm{e} 7 \mathrm{~cm}^{-3}$

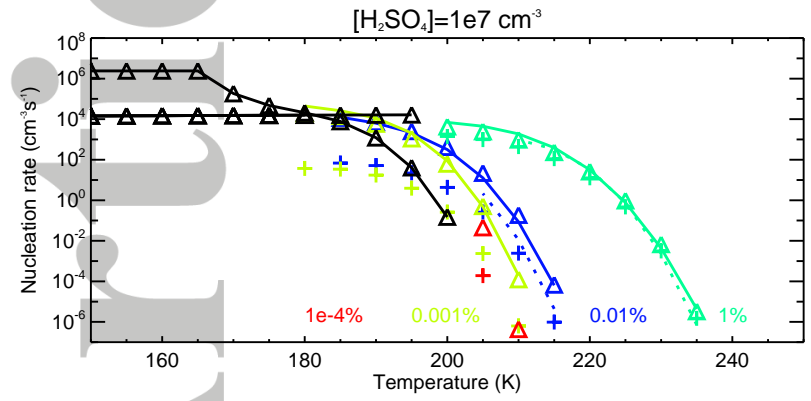

$\left[\mathrm{H}_{2} \mathrm{SO}_{4}\right]=1 \mathrm{e} 10 \mathrm{~cm}^{-3}$

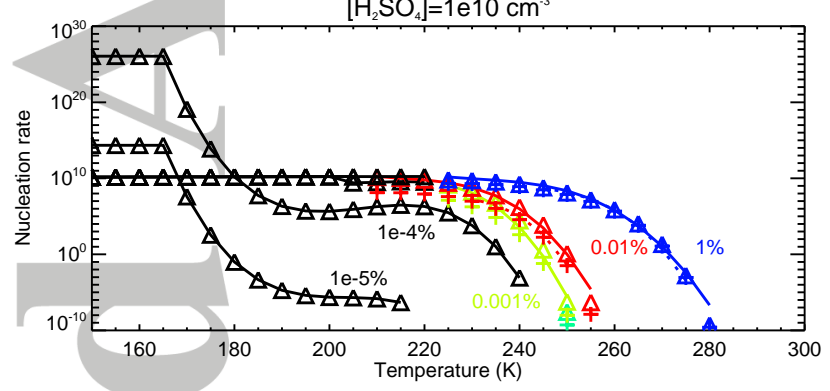

$\left[\mathrm{H}_{2} \mathrm{SO}_{4}\right]=1 \mathrm{e} 13 \mathrm{~cm}^{-3}$

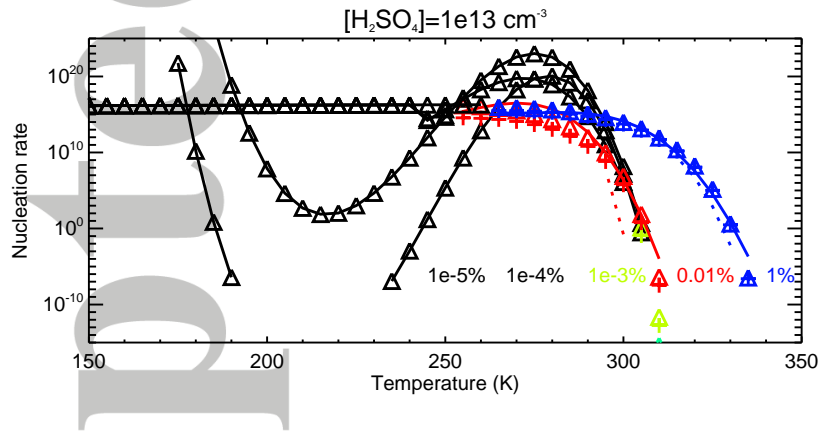

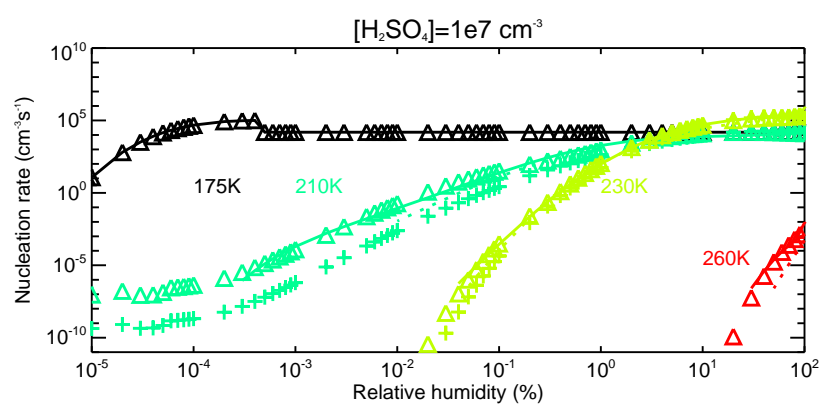

$\left[\mathrm{H}_{2} \mathrm{SO}_{4}\right]=1 \mathrm{e}^{-10 \mathrm{~cm}^{3}}$

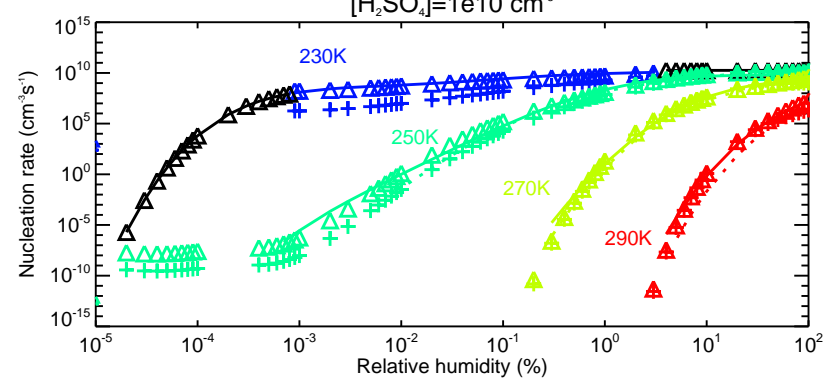

$\left[\mathrm{H}_{2} \mathrm{SO}_{4}\right]=1 \mathrm{e} 13 \mathrm{~cm}^{3}$

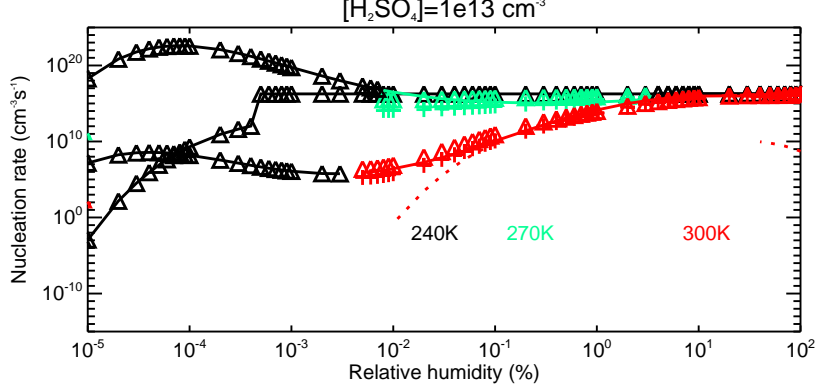

Figure 9. As Fig. 2, but for Venus-like low relative humidity conditions and sulfuric acid concentrations. 
$\left[\mathrm{H}_{2} \mathrm{SO}_{4}\right]=1 \mathrm{e} 7 \mathrm{~cm}^{-3}$ Nion $=4000 \mathrm{~cm}^{-3}$
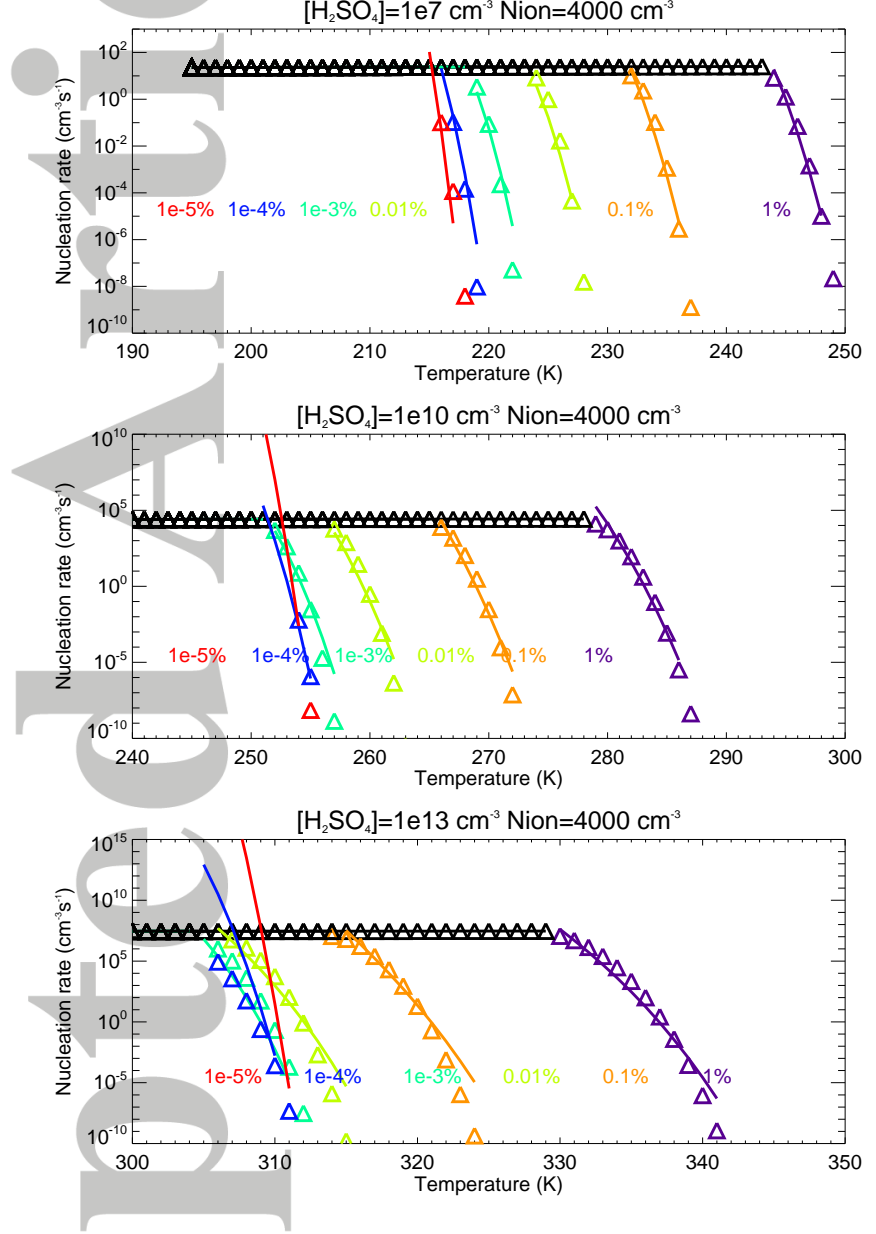

$\left[\mathrm{H}_{2} \mathrm{SO}_{4}\right]=1 \mathrm{e} 7 \mathrm{~cm}^{-3}$ Nion $=4000 \mathrm{~cm}^{3}$

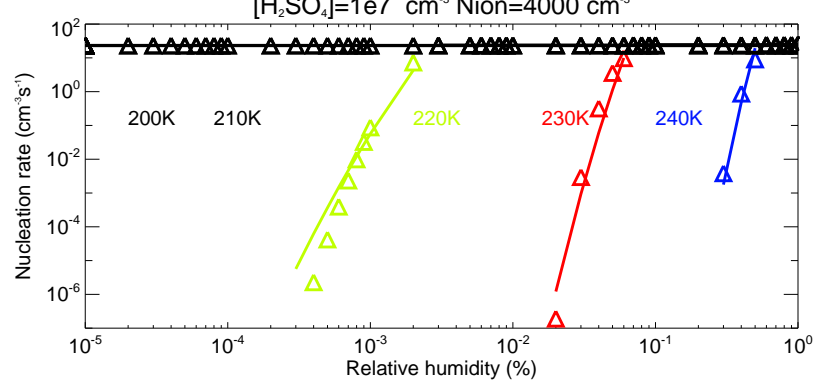

$\left[\mathrm{H}_{2} \mathrm{SO}_{4}\right]=1 \mathrm{e} 10 \mathrm{~cm}^{-3}$ Nion $=4000 \mathrm{~cm}^{-3}$
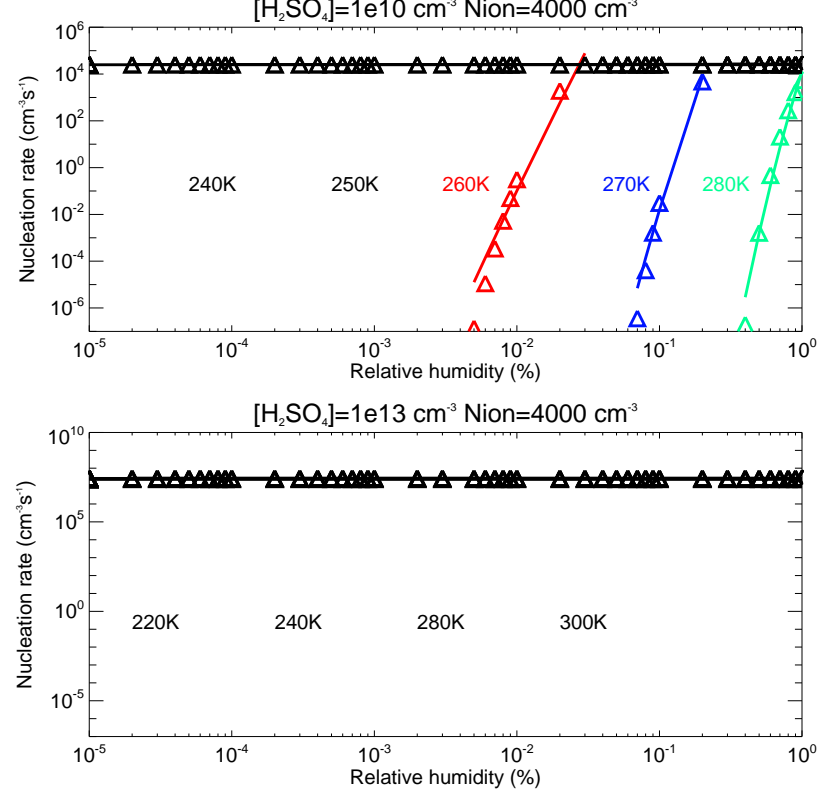

Figure 10. As Fig. 6, but for Venus-like low relative humidity conditions and sulfuric acid concentrations. 